Florida International University

FIU Digital Commons

FIU Electronic Theses and Dissertations

University Graduate School

$11-12-2013$

\title{
The Use of Visualization, Onset-and-Rime, Story Read-Alouds, and Discussion to Improve Diverse First Graders' Vocabulary and Comprehension
}

Virginia Lynn Shoup Holderness

Florida International University, giniholderness@gmail.com

DOI: $10.25148 /$ etd.FI13120908

Follow this and additional works at: https://digitalcommons.fiu.edu/etd

Part of the Curriculum and Instruction Commons

\section{Recommended Citation}

Holderness, Virginia Lynn Shoup, "The Use of Visualization, Onset-and-Rime, Story Read-Alouds, and Discussion to Improve Diverse First Graders' Vocabulary and Comprehension" (2013). FIU Electronic Theses and Dissertations. 1007.

https://digitalcommons.fiu.edu/etd/1007 


\section{FLORIDA INTERNATIONAL UNIVERSITY}

Miami, Florida

\section{THE USE OF VISUALIZATION, ONSET-AND-RIME, STORY READ-ALOUDS, AND DISCUSSION TO IMPROVE DIVERSE FIRST GRADERS' VOCABULARY AND COMPREHENSION}

A dissertation submitted in the partial fulfillment

of the requirements for the degree of

DOCTOR OF EDUCATION

in

CURRICULUM AND INSTRUCTION

by

Virginia Lynn Shoup Holderness 
To: Dean Delia C. Garcia

College of Education

This dissertation, written by Virginia Lynn Shoup Holderness, and entitled The Use of Visualization, Onset-and-Rime, Story Read-Alouds, and Discussion to Improve Diverse First Graders' Vocabulary and Comprehension, having been approved in respect to style and intellectual content, is referred to you for judgment.

We have read this dissertation and recommend that it be approved.

Eric Dwyer

Paulette Johnson

Lynne Miller

Joyce Fine, Major Professor

Date of Defense: November 12, 2013

The dissertation of Virginia Lynn Shoup Holderness is approved.

Dean Delia C. Garcia

College of Education

Dean Lakshmi N. Reddi

University Graduate School

Florida International University, 2013 
C Copyright 2013 by Virginia Lynn Shoup Holderness

All rights reserved. 


\section{DEDICATION}

I dedicate this dissertation to the three most important people in my life. To my dad, Wilson E. Shoup, whose love of higher education was a constant inspiration my whole life. To my daughter, Britt, who challenged me to race her to become a doctor. She won the race and became an M.D., but has continued to support me in my endeavor. And to my son, Clay, who constantly supported me and cheered me on with great enthusiasm. 


\section{ACKNOWLEDGMENTS}

I would like to thank my dissertation committee for their patience and persistence in working with me on this project. Dr. Fine constantly supported my effort, teaching me so much along the way. She never wavered, and was always willing to help me achieve this goal. She was a constant inspiration. Thank you, Dr. Fine. I would like to thank Dr. Johnson for her continued support and timely feedback. I would like to thank Dr. Miller, who was available to give feedback, and was willing to help at a moment's notice. I would like to thank Dr. Dwyer for relevant and timely feedback and kind words of encouragement.

I would like to thank my friends Jan Burtscher and Liliana Pin, who encouraged me at all times. I would like to thank Dr. Cynthia Moredock Januska for her encouragement.

I would like to thank Mr. Oslay Gil, Principal. He went above and beyond to help facilitate my study.

Finally, I want to thank my family, Britt and Clay, for encouraging me to attain my goal...to reach the highest pinnacle of education. With your support, I did it! Thank you! 


\section{ABSTRACT OF THE DISSERTATION \\ THE USE OF VISUALIZATION, ONSET-AND-RIME, STORY READ- ALOUDS, AND DISCUSSION TO IMPROVE DIVERSE FIRST GRADERS' VOCABULARY AND COMPREHENSION \\ by}

Virginia Lynn Shoup Holderness

Florida International University, 2013

Miami, Florida

Professor Joyce Fine, Major Professor

It has long been known that vocabulary is essential in the development of reading. Because vocabulary leading to increased comprehension is important, it necessary to determine strategies for ensuring that the best methods of teaching vocabulary are used to help students make gains in vocabulary leading to reading comprehension. According to the National Reading Panel, multiple strategies that involve active engagement on the part of the student are more effective than the use of just one strategy.

The purpose of this study was to determine if students' use of visualization, student-generated pictures of onset-and-rime-patterned vocabulary, and story read-alouds with discussion, would enable diverse first-grade students to increase their vocabulary and comprehension. In addition, this study examined the effect of the multimodal framework of strategies on English learners (ELs).

This quasi-experimental study $(N=69)$ was conducted in four first-grade classrooms in a low socio-economic school. Two treatment classes used a multimodal framework of strategies to learn weekly vocabulary words and comprehension. Two 
comparison classrooms used the traditional method of teaching weekly vocabulary and comprehension. Data sources included Florida Assessments for Instruction in Reading (FAIR), comprehension and vocabulary scores, and weekly MacMillan/McGraw Hill Treasures basal comprehension questions and onset-and-rime vocabulary questions.

This research determined that the treatment had an effect in adjusted FAIR comprehension means by group, with the treatment group (adj $M=5.14$ ) significantly higher than the comparison group (adj $M=-8.26$ ) on post scores. However, the treatment means did not increase from pre to post, but the comparison means significantly decreased from pre to post as the materials became more challenging. For the FAIR vocabulary, there was a significant difference by group with the comparison adjusted post mean higher than the treatment's, although both groups significantly increased from pre to post. However, the FAIR vocabulary posttest was not part of the Treasures vocabulary, which was taught using the multimodal framework of strategies. The Treasures vocabulary scores were not significantly different by group on the assessment across the weeks, although the treatment means were higher than those of the comparison group. Continued research is needed in the area of vocabulary and comprehension instructional methods in order to determine strategies to increase diverse, urban students' performance. 


\section{TABLE OF CONTENTS}

CHAPTER

PAGE

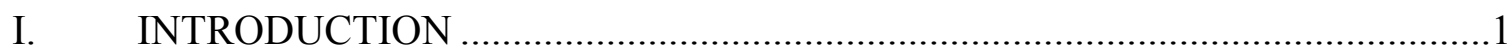

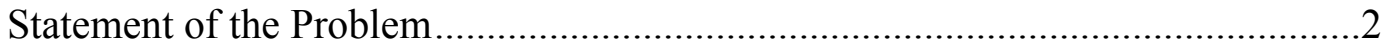

Statement of the Purpose ...............................................................................

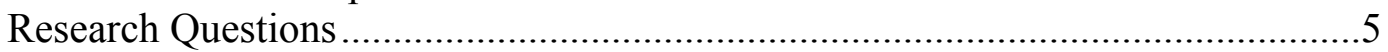

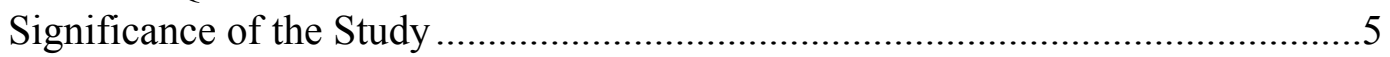

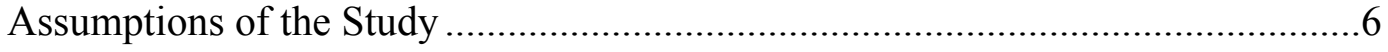

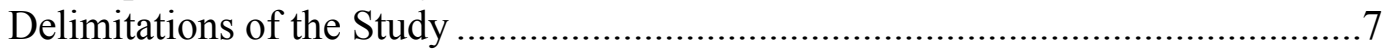

Operational Definition of Terms................................................................

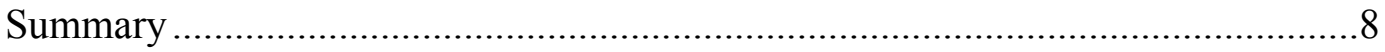

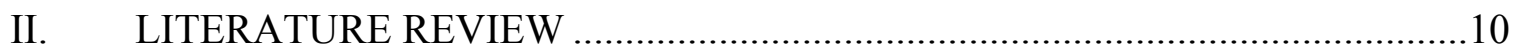

Background of the Study .........................................................................10

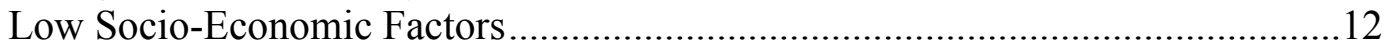

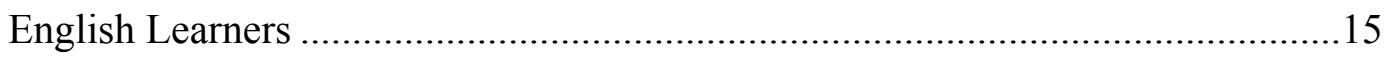

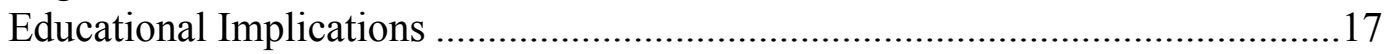

Vocabulary and Comprehension....................................................................19

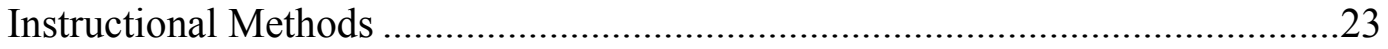

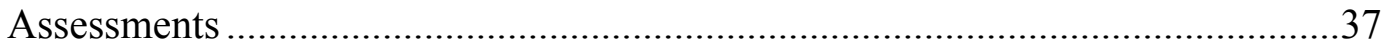

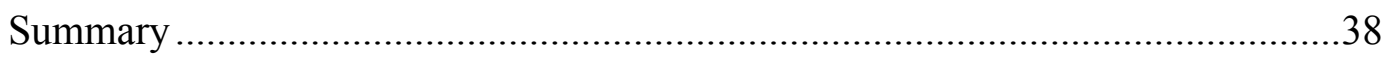

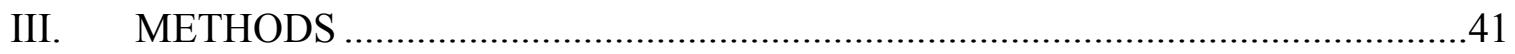

Purpose of the Study …………………....................................................

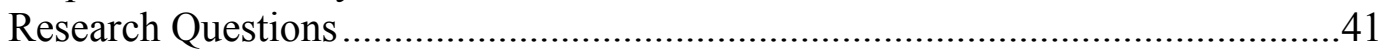

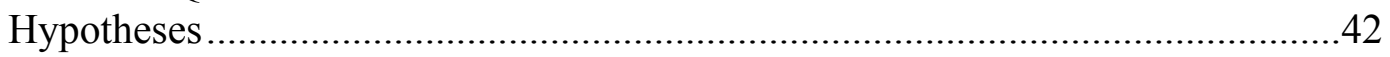

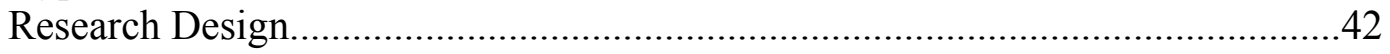

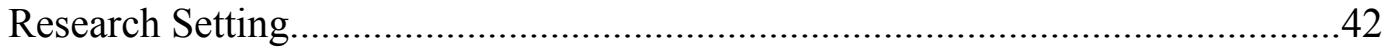

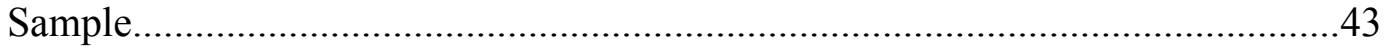

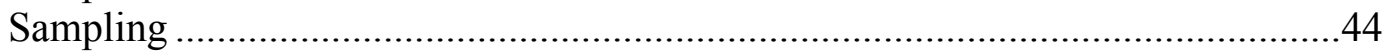

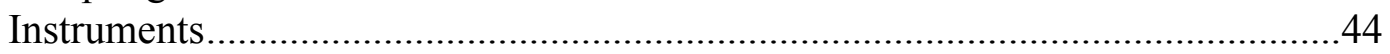

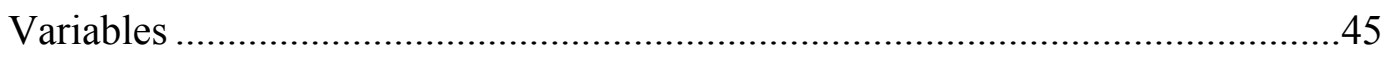

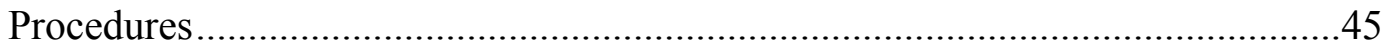

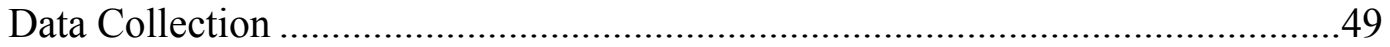

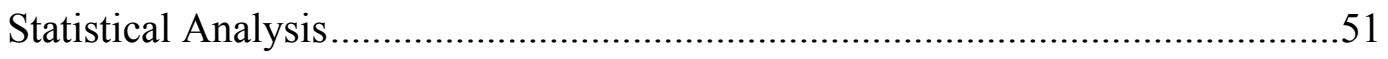

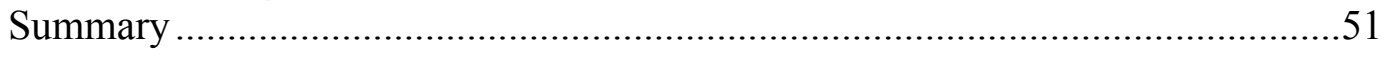

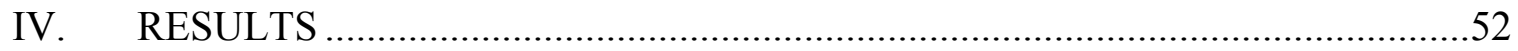

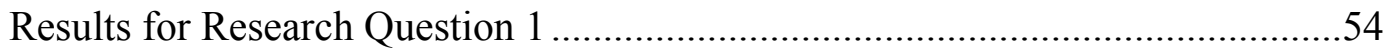

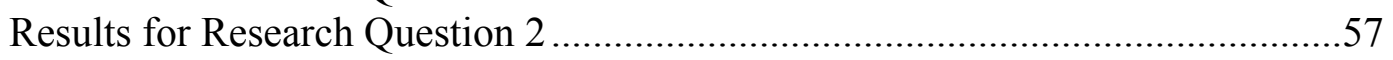

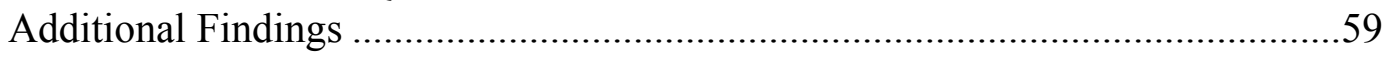

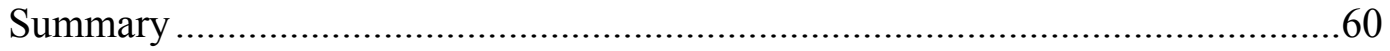




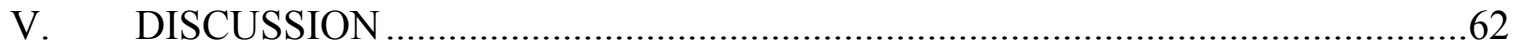

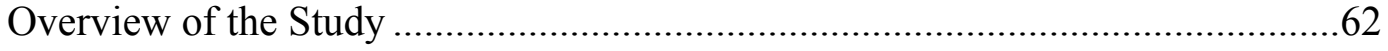

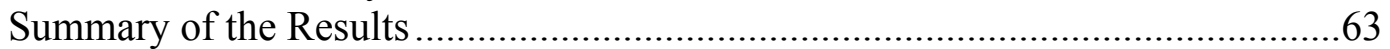

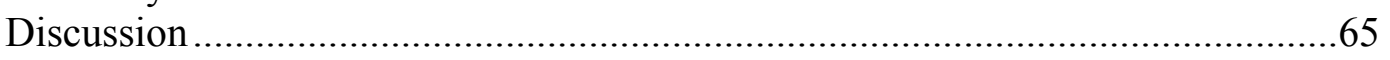

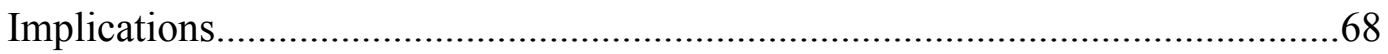

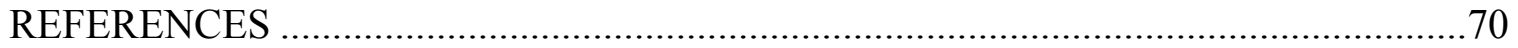

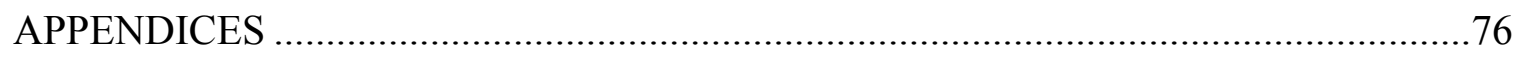

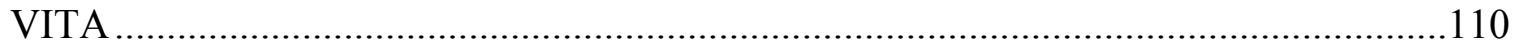




\section{LIST OF TABLES}

TABLE

PAGE

1. Frequencies of Students Participating in the Study by Treatment, Class and EL Status.

2. Data Collection

3. English Learner Status by Group

4. Pretest Means (SDs) of the FAIR Comprehension, FAIR Vocabulary, and Treasures Vocabulary....

5. Observed and Adjusted Mean Gains for FAIR Comprehension, FAIR

Vocabulary, and the Treasures Vocabulary by Group .55

6. Adjusted Mean Gains for Treasures Vocabulary by Group and English Learner Status. .58

7. Weekly Means of Treasures Story Comprehension Tests by Group .59

8. Weekly Means of Treasures Vocabulary Comprehension by Group..... .60 


\section{CHAPTER I}

\section{INTRODUCTION}

It has long been known that vocabulary is essential in the development of reading comprehension (Davis, 1942). In the report of the National Reading Panel (NRP, 2000), it is stated that vocabulary knowledge is essential in the development of reading skills. It went on to say that as early as 1925 , growth in reading meant growth in word knowledge (National Reading Panel, 2000). Further, the National Reading Panel stated that, "reading comprehension is a cognitive process that integrates complex skills and cannot be understood without examining the critical role of vocabulary learning and instruction, and its development..." (National Reading Panel, 2000, ch.4, p.1). The National Reading Panel concluded its section on vocabulary instruction by stating that certain strategies impact the process of vocabulary acquisition and that vocabulary learning is more effective when accompanied by the active engagement of the student. According to the National Reading Panel, multiple strategies that involve active engagement on the part of the student are more effective than the use of just one strategy (National Reading Panel, 2000).

The exact relationship between vocabulary, or word knowledge, and comprehension, the understanding of text, has been debated since the first half of the twentieth century, but there is general agreement that vocabulary is most definitely linked to comprehension (Bauman, 2009). In fact, research indicates that a larger, more comprehensive vocabulary can lead to increased comprehension (Beck \& McKeown, 2007; Coyne, Simmons, Kame'enui, \& Stoolmiller, 2004; Cunningham \& Stanovich, 1997; Juel \& Deffes, 2004; Maynard, Pullen, \& Coyne, 2010; National Reading Panel 
Report, 2000). Unfortunately, a major factor in school failure, especially of disadvantaged students, seems to be inadequate vocabulary, or lack of verbal knowledge (Becker, 1977). The current study was designed to support diverse young readers' vocabulary acquisition, leading to improved reading comprehension, through the use of a multimodal strategy that required their active engagement.

\section{Statement of the Problem}

Children come to school with varying degrees of vocabulary knowledge (Hart \& Risley,1995; Juel \& Deffes, 2004). Added to the problem of learning vocabulary is the fact that many students come to school with limited prior background knowledge and few verbal and reading experiences to build upon (Graves, 2006). Bilingual students from low socio-economic backgrounds may be at an increased risk for reading difficulties due to their limited English vocabularies (Ucelli \& Paez, 2007). Low socio-economic elementary students may lack opportunities to build a substantial vocabulary due to their living circumstances and, presumably, their parents' lack of resources for books and educational experiences for their children. Because the depth of students' vocabulary is an indicator of reading ability in future grades (Biemiller \& Boote, 2006; Blachowicz, Fisher, Ogle, \& Watts-Taffe, 2006), quality vocabulary instruction is imperative. It has been shown that using multiple strategies has a greater effect on students than using just one strategy (Blachowicz et al., 2006; McKeown \& Beck, 1988). Therefore, by using a multimodal strategy, young readers will have the opportunity to actively engage in vocabulary development through the use of specific interconnecting and reinforcing experiences. Additionally, when teaching young, diverse readers it is important to select vocabulary from their instructional materials. By doing this, the young readers have 
multiple opportunities to apply their developing vocabulary knowledge within meaningful contexts.

The most commonly used reading instructional materials in today's classrooms are commercial reading series (Allington, 2002). While these reading series consist of basal reading textbooks that are designed for the majority students (Heibert, 2009), there is a growing poor and minority population in this country who have difficulty making progress in classrooms in which these basals are used (U. S. Census Bureau, 2010). The text in these materials lack features, such as enough repetition of vocabulary (Juel \& Roper/Scheider, 1985) to support beginning readers, especially at-risk students and Englishlearners (ELs), (Heibert \& Martin, 2009). Although textbook publishers have included features that give suggestions for instructional accommodations for EL students, these suggestions may not be focused on key vocabulary that students must learn.

Many textbooks are designed primarily for native speakers. For instance, there may be little development for the vocabulary selected as the focus for assessment. In an effort to accommodate changes in demographics, the authors have added in pronunciation suggestions for ELs for sounds that may not be native to their language. Also, the authors may have added names that may be more familiar to ELs, such as Juan, but with little real attention to modifications for the vocabulary needs of diverse students. While the vocabulary is not presented as lexical sets, opposites, or free associates, which have been found to be more difficult for ELs to learn (Nation, 2000), the presentation of vocabulary does not build depth of concept knowledge for words. Instead, the materials in the basal consist of perhaps two to three phonograms and multiple onsets to go with 
the rimes. The focus is to build vocabulary upon the rimes from week to week. This lacks the concrete concept - building instructional methods needed by diverse learners.

Teachers working with at-risk young readers in urban schools need to address this problem. It is important to find strategies to support vocabulary acquisition that are effective and beneficial to diverse, low socio-economic first-grade students. Integrating strategies for vocabulary instruction from several studies may provide a useful multimodal approach. First, a multiple strategy dialogic approach has been identified as promising by Wilkinson and Son (2010). This strategic approach emphasizes the importance of providing students with opportunities to use vocabulary in discussions, thus enhancing comprehension through use of the words. Second, in 1998, Opitz and Rasinski wrote about how effective oral reading strategies impact vocabulary growth. One of the strategies they thought worthwhile was the teacher read-aloud. When reading to at-risk students, the authors suggested that the teacher practice beforehand and use exaggerated voices that emphasize key vocabulary. They stated that students need to hear books read aloud in order to understand what is happening as they hear vocabulary items for the first time, or revisit them. According to Opitz and Rasinski (1998), any instruction, regardless of the student's age, should include teacher read-alouds and discussion of the reading, especially for at-risk students. Third, visualization, in the form of pictures, is relied upon by students throughout their day. According to Beck and McKeown (2001) students can more easily glean information from pictures than from text language. It is hoped that by using a multimodal strategy that incorporates vocabulary interventions found effective by other researchers, the vocabulary development of young, at-risk readers may be positively impacted. 


\section{Statement of the Purpose}

The purpose of this study was to determine the effectiveness of using a multimodal strategy to increase diverse students' vocabulary acquisition, leading to improved reading comprehension. Specifically, this researcher sought to examine:

1. The overall effect of the multimodal vocabulary strategy on young, at-risk readers' vocabulary acquisition and reading comprehension; and,

2. The effect of the multimodal vocabulary strategy on young, at-risk EL readers' vocabulary acquisition and reading comprehension.

\section{Research Questions}

1. Will visualization, student-generated pictures for onset-and-rime-patterned vocabulary, and story read-alouds including those words, and discussion focusing on those words, improve first-grade students' comprehension and vocabulary compared to a comparison group receiving traditional instruction?

2. Will comprehension and vocabulary gains for first grade students using visualization, which includes student-generated pictures for onset-and-rimepatterned vocabulary, and story read-alouds including those words, and discussion focusing on those words, and a comparison group receiving traditional instruction differ between EL students in the treatment group and EL students in the comparison group?

\section{Significance of the Study}

The gap in vocabulary knowledge between economically disadvantaged and Economically-advantaged students begins very early in life. It is a significant problem for many urban students, often affecting their later school years (Coyne et al., 2004; Hart \& 
Risley, 1995). Students coming to school with a vocabulary deficit need help. English language learners coming to school with a deficit exacerbates the problem for these students. The current study contributes to the research knowledge base in that it introduces a research-based multimodal strategy that may positively impact the vocabulary development of young, at-risk readers.

It has been shown that multiple strategies have a greater effect on students than using just one strategy (Blachowicz et al., 2006; McKeown \& Beck, 1988). This study provides research evidence that demonstrates that a multimodal vocabulary strategy, involving visualization, teacher read-alouds, and teacher-student discussion, may contribute somewhat to at-risk readers' vocabulary acquisition leading to reading comprehension.

According to Adams (1990), cognitive psychologists agree that word meaning is comprised of many types of features and associations that accumulate due to the reader's experiences with words in context and the concepts to which they refer. Through the use of visualization in the form of student-generated pictures, along with onset-and-rimepatterned vocabulary words and story read-alouds with discussion focusing on those words, the current study contributed to the research knowledge base by examining the use

of a multimodal vocabulary strategy that engaged young readers in a variety of experiences where the vocabulary words were used in meaningful contexts.

\section{Assumptions of the Study}

An underlying assumption was that the assessment instruments used in this study measure vocabulary and comprehension improvement. Another underlying assumption 
was that this group of at-risk, diverse students who took part in this study are representative of urban first-grade students elsewhere.

\section{Delimitations of the Study}

The sample was comprised of the currently enrolled first-grade students in an urban, public, elementary school, where most of the students were scoring poorly on the weekly vocabulary and comprehension tests. The school participating in this study has $95 \%$ of its students receiving free or reduced breakfast and lunch. The school is classified as a Title I school, indicating that it is categorized as a low socio-economic school. The researcher set up a study using visualization, student-generated pictures of onset-and-rime-patterned vocabulary, and story read-alouds with discussion using those vocabulary words, to improve diverse first graders' vocabulary and comprehension. Vocabulary lists for this study were delimited to the mandated onset-and-rime words from the first grade reading series, Treasures for First Grade, currently used in this urban school. The weekly story tests were also delimited by the mandated tests from the Treasures series. Read-alouds were delimited by the mandated books that came with the basal series, Treasures for First Grade.

\section{Operational Definition of Terms}

Comprehension. The reconstruction of the intended meaning of a communication; accurately understanding what is written (Harris \& Hodges, 2005, p. 38), as measured by the Florida Assessments for Instruction in Reading and Treasures for First Grade. 
Diverse Populations in Schools. Diverse populations in schools means children of color, low income children, English learners, and children in urban and rural settings (Hollis \& Guzman, 2005, p. 477).

Onset. "The consonants preceding the vowel of a syllable" (Harris \& Hodges, 2005, p. 170).

Rime. "A vowel and any following consonants of a syllable" (Harris \& Hodges, 2005, p. 221).

Scaffolding. "In learning, the gradual withdrawal of adult support, as through instruction, modeling, questioning, and feedback for a child's performance across successive engagements, thus transferring more and more autonomy to the child" (Harris \& Hodges, 2005, p. 226).

Visualization. "The process, or result, of mentally picturing objects that are normally experienced directly" (Harris \& Hodges, 2005, p. 274).

Vocabulary. "Those words known by a group" (Harris \& Hodges, 2005, p. 274), as measured by the Florida Assessments for Instruction in Reading and Treasures for First Grade.

\section{Summary}

A multimodal instructional framework of strategies was designed to help firstgrade students learn vocabulary and improve comprehension during their school day. South Florida, where this urban school is located, has a rapidly growing population of EL students enrolled in its school systems. The neighborhood where this urban school is located is primarily a low socio-economic area, with mostly poor and working class people and families. First-grade students were the subjects taking part in this research 
study using visualization, which included student-generated pictures of onset-and-rime patterned vocabulary, and story read-alouds with discussion using those words, in a multimodal instructional framework.

Chapter 2 presents a review of the literature with a discussion of key elements of vocabulary acquisition, including socio-economic status and second language learners. Chapter 3 describes the setting, the sample, the instruments, the procedure, the data collection, and methods. Chapter 4 presents the results of the data analyses based on the research questions from this study. Chapter 5 presents a discussion and interpretation of the findings and implications for further research. 


\section{CHAPTER II}

\section{LITERATURE REVIEW}

\section{Background of the Study}

This chapter presents the literature related to this study. Several issues will be discussed. The first area of research to be covered will be the area concerning children from low socio-economic homes, who have limited vocabularies and issues associated with this problem. Current views surrounding the causes of low vocabulary levels, in conjunction with living in poverty, will be discussed. Also to be looked at are the English learners (ELs) who not only encounter a language barrier, but grow up in low socio-economic neighborhoods. Another area of research will review the educational implications for children with limited vocabularies growing up in poverty. Areas to be discussed related to children from low socio-economic homes having limited vocabularies, and factors related to this problem, include the challenges and consequences of a child with a low vocabulary becoming proficient in reading comprehension. The final section will outline evidence supporting methods of vocabulary and comprehension instruction that are effective in development of those skills for all children, including those from low socio-economic homes. The chapter will conclude with a discussion of current assessment methods.

It has been shown in past research studies that the depth of a student's vocabulary is an indicator of reading comprehension (Beck, McKeown, \& Kucan, 2002; Berne \& Blachowicz, 2009; Coyne et al., 2004; Nagy \& Scott, 2000). Beck, et al. (2002), stated that an excellent vocabulary is needed for a good education. Adams (2011) noted that students must continue to learn more vocabulary in order to understand more advanced 
text. Therefore, vocabulary acquisition is a vital component of every student's education, and strong and varied strategies must be found and implemented in order to improve students' vocabulary, leading to improved comprehension.

The National Reading Panel (NRP, 2000) reported that many studies placed more emphasis on comprehension than vocabulary, even though vocabulary appeared to be related to increasing comprehension. That same idea was echoed by Brabham and Villaume (2002), who also found that not enough emphasis was being placed on the importance of vocabulary instruction. A robust vocabulary has been linked to more fluent reading and improved comprehension (Beck, Perfetti \& McKeown, 1982; Blachowicz, et al., 2006; Coyne, et al., 2004; NRP, 2000; Stahl \& Nagy, 2006). Vocabulary and comprehension are critical needs for students. According to some researchers (Blachowicz et al., 2006), reading was the single most important skill that a child would learn, and the task of learning to read either began or was expanded in first grade. For some children, this task can be a difficult one, one that impacts the rest of their school careers, extending into their adulthood. Research suggested that children's reading comprehension was improved by increasing vocabulary (Adams, 2011; Bryant, Goodwin, Bryant \& Higgins, 2003). The future is not bright for the at-risk reader who does not receive help in the area of vocabulary acquisition (Biemiller \& Boote, 2006; Hart \& Risley, 1995).

Beck, McKeown, and Kucan (2002), leading researchers in the field of vocabulary, related that a "large and rich vocabulary is the hallmark of an educated individual" (Beck et al., 2002, p. 1). They made the observation that vocabulary knowledge varies widely among students from different socio-economic groups, and that 
once this is established, it is difficult to change. They believed that there was not enough instruction in the area of vocabulary being conducted in public schools, and that robust, vigorous and strong vocabulary instruction was imminently needed (Beck et al., 2002).

\section{Low Socio-Economic Factors}

\section{Limited Vocabulary}

Limited vocabularies in children from families on welfare, living in poverty, or living in low socio-economic situations has been compared by researchers to the higher vocabularies of children from higher socio-economic status (Hart \& Risley, 1995). This issue is often referenced by researchers studying vocabulary and vocabulary instruction. The empirical evidence that exists on this subject provides theoretical ideas about the causes of the lower vocabularies in children coming from low socio-economic homes. Many of the studies that are available provide information concerning causes of the low vocabulary levels in children from poorer households. Researchers have detected that vocabulary differences have been discovered as early as the toddler age (Beck \& McKeown, 2007; Hart \& Risley, 1995).

Many references are made concerning the issue of the limited vocabulary of children from low socio-economic homes. Researchers Hart and Risley (2003) stated that vocabulary use in children three years old was indicative of their vocabulary and language use at age nine, which was reflected on the Peabody Picture Vocabulary Test (PPVT). Both Juel, Biancarosa, Coker, and Deffes (2003), and Stahl and Stahl (2004) suggested that students from low socio-economic homes knew about 6,000 fewer words than their middle class peers when starting school. Stahl and Stahl interjected the fact that the vocabulary gap was continuing to widen. As stated, the gap can be attributed to 
different socio-economic realities. Children living in poverty tend to score one standard deviation lower on tests of vocabulary and sentence complexity than children from higher socio-economic situations (Restrepo, Schwanenflugel, Blake, Neuharth-Pritchett, Cramer, \& Ruston, 2006). In a related report, Sharif, Ozuah, Dinkevich, and Mulvihill (2003) reported that children from low socio-economic homes were at a much higher risk for reading failure and other related school problems than children from higher socioeconomic homes and neighborhoods.

\section{Possible Causes of Limited Vocabulary}

Being able to determine the causes for the discrepancies in low and high vocabulary levels of children will be a useful tool in the fight to eradicate the differences of those levels. One of the well-known studies discussing the causes of the differences in vocabulary levels was a study conducted by Hart and Risley in 1995. These researchers conducted a study that determined that there was a discrepancy in the accumulated vocabulary among professors' children and children living in poverty. They did a longitudinal study of children from 42 families for two and one-half years, and found that children followed in their parents' footsteps in their developmental tracks. It was found that a child from a high socio-economic status home consistently received three times more experiences with language and interaction, and knew substantially more words than did a child from a low socio-economic status home (Hart \& Risley, 1995). The researchers continued to find that more needed to be done to give all children rich experiences in the early years of their lives in order to enhance vocabulary (Hart \& Risley, 2003). 
Hart and Risley also found that the amount and quality of talk were affected by circumstances in the homes. There were challenges present in the lower socio-economic homes that were not present in the homes of higher economic status. Parents on welfare had daily survival challenges that the higher socio-economic parents did not have, and often did not have the money or time to expose their children to varied experiences, such as literary and cultural events, and books (Hart \& Risley, 1995). These factors can limit the amount of talk time, hence limiting the increase in outside experiences and vocabularies.

Qi, Kaiser, Milan, and Hancock (2006) carried out a longitudinal study that explored the connection between socio-economic status and language ability compared to different demographic factors. Maternal education level was found to be a strong factor contributing to language ability. If a mother did not graduate from high school, her children scored approximately five points lower on the Peabody Picture Vocabulary Test-III (PPVT-III) than a child whose mother had some college education, and eleven points lower than a child whose mother had a college degree. Another factor the researchers found was that the marital status of the parents had an influence on the child's language ability. Children from single parent homes scored five points lower on the PPVT-III than children who came from a two parent home. The number of children in a home also played a role in scores on the PPVT-III. Children from families of three or more children scored lower than children in families of two or less children. The researchers also found that children from lower socio-economic homes were more likely to have a mother without much education and a single parent home (Qi, Kaiser, Milan, \& Hancock, 2006). These findings are similar to the reasons for limited vocabulary found 
by Hart and Risley in 1995. Challenges exist for children from low socio-economic homes whose mothers have little education and are single parents.

Coyne et al. (2004) pointed to the fact that many children start school with many hours of language experiences to draw upon, which translates to a richer, higher level vocabulary. The amount of language experience before starting school has a direct effect on the vocabulary level of the child. The lower socio-economic homes produce children who do not reap the benefit of rich language experiences before entering school, and the children of higher economic status do get those extra years of experience with language and books. Researchers Sharif et al. (2003) agreed with the fact that children from lower socio-economic status homes were at greater risk for failure in reading and reading comprehension. To add to the vocabulary differences and their causes, Biemiller and Slonim (2001) found that the most influential difference in vocabulary learning until grade three was the difference in experiences. This finding is in line with the findings of Hart and Risley (1995) and Qi et al. (2006). Biemiller and Slonim (2001) believed that the differences in vocabulary level were a cumulative result of experiences that the child received from parents and caregivers, in combination with how the child processed vocabulary.

\section{English Learners}

\section{Language Barrier}

English learners (ELs) are often at risk because of the language barrier they face. Their situation is exacerbated if those EL students come from a low socio-economic setting (Uccelli \& Paez, 2007). To add to the problem, parents of EL students often do not have a good command of the English language, so they are unable to help their 
children with their schoolwork. Often, EL students come to school with much different background knowledge than their native language speaking counterparts, putting them at an immediate deficit in the school setting. English language proficiency is noted by Uccelli \& Paez (2007) as being extremely important in bilingual students' literacy development. The authors assert that bilingual students, with the added problem of low socio-economic status, may be at risk for reading difficulties due to their limited vocabularies. Low socio-economic status, coupled with English language learning is a double deficit for the English learners.

\section{Low Socio-Economic Status}

Blachowicz et al. (2006) stated that there is a gap in the vocabulary knowledge of children from economically disadvantaged parents and schools. Vocabulary knowledge is also a critical factor in the school success of English learners (ELs). The authors say that knowledge of English language vocabulary is one of the strongest indicators of the discrepancy between reading performance of native English speakers and ELs. This remains a factor even though ELs may have a robust vocabulary in their native language. They are at a deficit when it comes to English language learning. When academic terms are used in school, the EL will have trouble with the specialized meanings of terms. This is a problem for many students who need to use academic vocabulary (Graves, 2006).

When EL status is added to low socio-economic status, students have to overcome even greater obstacles in their quest for vocabulary acquisition. 


\section{Educational Implications}

\section{Low Socio-Economic Status}

Current research has revealed several factors that contribute to lower vocabulary levels in children from low socio-economic homes, and most relate to socio-economic status. Level of parental education and number of parents in the home also affect the children. Stahl and Stahl (2004) made note of the fact that the vocabulary level gap is

ever widening, despite the fact that schools are aware of the difficulties brought about by lower socio-economic situations. Educational implications are bleak for future school achievement of children from low socio-economic status homes.

\section{Limited Vocabulary}

Research suggests that there is a causal connection between vocabulary knowledge and reading comprehension. It suggests that vocabulary knowledge leads to better reading and better comprehension, and that a child who starts school with a limited vocabulary continues at a deficit (Beck \& McKeown, 2007; Blachowicz \& Fisher, 2004; Juel \& Deffes, 2004). Becker (1977) stated that a major factor in failure in school by disadvantaged students was a direct result of insufficient vocabulary.

Cunningham and Stanovich (1997) conducted a longitudinal study on students first assessed in reading in the first grade, and again in reading in the eleventh grade, using a battery of tests. The researchers found that the first-grade assessments were accurate indicators of eleventh-grade achievement. The vocabulary level of the firstgrade students was a good indicator of their reading success in eleventh grade. This is an indication that effective interventions and a multimodal instructional framework of strategies are needed in first grade. 
Beck and McKeown (2007) reported that low vocabulary levels and poor reading comprehension can affect all facets of a child's life and future. Stahl and Nagy (2006) agreed and stated that a person's vocabulary level helps or hinders access to sources of information that will have future implications. Both sets of researchers concluded that a solid vocabulary was the key to success in education.

When a child is raised in poverty, there are educational implications. Hart and Risley (1995) became concerned with not only the smaller vocabularies of the children from low socio-economic homes, but also with the flatter growth curves seen as the children grew. The Turner House children added to their vocabulary stock at a much slower pace than the children of the professors. They projected trajectories of growth into the future, and those trajectories indicated ever widening gaps between the low socio-economic students and the professors' children. Therefore, Hart and Risley (1995) surmised that vocabulary at age three was linked to the family socio-economic status. These findings from the studies of Hart and Risley (1995) indicated that children living in poverty were at risk for reading failure, and possibly school failure. As mentioned earlier, a study conducted by Cunningham and Stanovich (1997) showed that vocabulary level at school entry was an early indicator of vocabulary level and reading comprehension level in eleventh grade. Hart and Risley (1995) along with Cunningham and Stanovich (1997) have provided information about what contributes to vocabulary acquisition, and what some of the long lasting effects are on the school careers of these children.

The National Reading Panel Report (2000) contended that there was support for the statement that there was a connection between vocabulary level and reading 
comprehension over time. According to Stahl and Stahl (2004), the problem of limited vocabulary gets worse as the years progress. Students who start school with a good vocabulary will learn more vocabulary and be able to understand progressively harder textbooks. Students who start school with a vocabulary deficit will begin to fall further and further behind as the vocabulary bogs them down, and they cannot comprehend the textbooks. Biemiller (2004) supported that assumption by showing a correlation between vocabulary size and reading comprehension. The correlation, at .81 , showed that there was an important connection between vocabulary and reading comprehension all through the school years.

Research suggests that vocabulary knowledge can have a great effect on a child's schooling, even when the child is very young (Biemiller, 2004; Juel et al., 2003). The problem remains that young children from low socio-economic homes are at-risk because of their low entrance-level vocabulary. According to Stahl and Stahl (2004), the gap is widening. There is an urgent need to find a solution to the problem. Research based instructional techniques and a multimodal instructional framework of strategies need to be evaluated and employed in order to help students develop higher levels of vocabulary knowledge in order to help increase comprehension.

\section{Vocabulary and Comprehension}

The National Reading Panel (2000) stated that students needed both vocabulary and comprehension instruction. The Panel maintained that vocabulary was considered to be individual words, while comprehension was considered to be much larger pieces. In order to comprehend, a student needed to know individual words. Separating the two was "difficult, if not impossible" (NRP, 2000, 4-15). An important component of 
Anderson and Freebody's Aptitude Position, which stated that vocabulary and comprehension were both affected by strong verbal aptitude, involved the student's ability to contemplate and manipulate language (p. 32). This contemplation and manipulation can be achieved using multiple vocabulary instruction strategies, or a multimodal instructional frame.

Anderson and Freebody (1981) suggested three hypotheses to explain the high correlation between comprehension and vocabulary. The first was the Instrumentalist Theory. It argued that learning words caused comprehension. The next was the Verbal Aptitude Theory which suggested that general verbal ability is the cause of both vocabulary and comprehension. Finally, the Knowledge Hypothesis stated that both vocabulary and comprehension result from learning more vocabulary. All theories point out that vocabulary acquisition is indeed necessary for success in school.

Most experts agree that vocabulary is a very important aspect of a student's education. Without vocabulary, the student will become lost, and learning to read and comprehend will be much harder for him. In another article by Blachowicz and Fisher (2004), the authors stated that not only was it important to have a strong vocabulary to enhance reading and reading comprehension, but it was important in order to succeed in society. They labeled themselves authors and researchers of vocabulary, and have done numerous studies on the subject. They described some research-based practices for educators to use. One recommended strategy for word learning was word games. Art was another way for children to "play" with words. Using art was a way to represent a word visually and connect to the word kinesthetically (Blachowicz \& Fisher, 2004). As 
the children used art to "play" with words, they were using different strategies and varied modalities to enhance their word learning.

It has been speculated that looking up a word in the dictionary does not lead to the understanding of that word, therefore, it is not an effective word learning technique. Helping students develop a sizeable and powerful vocabulary is of utmost importance to their future success, both in school and in their lives after school. Effective vocabulary is attainable through professional instruction. According to the Texas Reading Initiative (2002), students may forget much of what they learn in school, but the words they learn will help them in their future. Many experts agree that a large vocabulary leads to better comprehension (Beck et al., 1982; Coyne et al., 2004; Cunningham \& Stanovich, 1997; National Reading Panel, 2000; Pearson, Hiebert, \& Kamil, 2007).

Use of new words in sentences was also seen as a useful and effective tool for learning new vocabulary words. This strategy was used in conjunction with semantic webbing. The Texas Reading Initiative (2002) stated that in learning vocabulary, use of semantic webbing, discussions, and peer study strategies were very helpful. The students were aided by the use of personal journals, where they practiced constructing sentences using the new vocabulary words. Vaughn-Shavuo (1990) also found that dictation of student sentences was a positive reinforcement for word learning.

Beck et al. (2002), also considered experts in the field of vocabulary and vocabulary instruction, asserted that multiple encounters with words was an important aspect of the student being able to comprehend and use words. The authors suggested "sprinkling" the classroom environment with rich words and print. They pointed out that possibly the students would not learn all of the words, but they would certainly not learn 
the words if they were not exposed to them. Exposure is an important way to introduce students to new words. Beck et al. (2002) stated that word use should be encouraged at school as well as at home. Students need to practice using their new vocabulary words in order to commit them to memory. The authors suggested games to play where students get points when they use a new word or hear it at home. The authors felt that these strategies made learning new vocabulary much more dramatic and exciting, therefore increasing interest in words.

In a study by Beck et al. (2002), the researchers found that students who learned vocabulary words and learned them well claimed what the authors called "word ownership." They knew the words and were comfortable using them, hence the term "word ownership." A phenomenon was noticed that with the vocabulary use and enrichment, came student interest in other words. Students began to notice vocabulary around them, and they were interested in using the new words and learning more words.

Past research has shown a strong connection between readers' vocabulary knowledge and their ability to comprehend what they read as far back as the early $20^{\text {th }}$ Century. Researchers have long suspected the important role that vocabulary plays in a student's ability to read and comprehend (Adams, 1990; Beck et al., 1982; Coyne et al., 2004; Cunningham \& Stanovich, 1997; National Reading Panel, 2000). These researchers reported that there was much less history of research on methods of vocabulary instruction. According to Becker (1977), school failure in disadvantaged areas was often due to a lack of vocabulary knowledge. There are educational implications for both high and low level vocabulary students, such as school success and high school completion. 


\section{Instructional Methods}

It would behoove schools to find appropriate and effective vocabulary instructional methods that work for all children, since vocabulary knowledge has an effect on reading, reading comprehension, and school success (Beck et al., 1982; Hart \& Risley, 1995). The problem of low vocabulary in low socio-economic homes needs to be addressed and remediated in order to provide a better future for the children. Biemiller (2004) felt that the gap was here to stay unless a vocabulary program was developed and used consistently in schools. Beck et al. (2002) stated that at the present time, there was not much vocabulary instruction being conducted in schools.

Vocabulary instruction is needed in the classroom today, according to a quote from an article by Blachowicz et al.

Historically, vocabulary instruction has been overshadowed by instruction in word recognition and comprehension; however, it is clearly an area of concern in its own right and, therefore, needs to become a priority in the instructional preparation and inservice professional development of classroom and content area teachers. It is important that teacher education at both the preservice and inservice levels include experiences that will provide teachers with a strong understanding of the underpinnings of vocabulary development, an array of strategies for teaching individual words and for teaching word-learning strategies for independence, and an appreciation for the role of word consciousness in vocabulary development and the way in which word consciousness can be fostered. (Blachowicz et al., 2006, p. 534)

Graves (2006) proposed an all-encompassing, theory based, four-component structure for comprehensive instruction. The components included providing rich and varied language experience, teaching individual words, teaching word-learning strategies, and promoting word consciousness (p. 5). Providing rich and varied language 
experiences includes active participation on the part of the students in vocabulary learning that focuses on target words (Blachowicz et al., 2006). Teaching individual words encompasses weekly vocabulary acquisition. Word-learning strategies incorporate the multimodal instructional framework of visualization, onset-and-rime, and story readalouds with discussion. Promoting word consciousness is incorporated in the multimodal instructional framework of strategies.

It has been established that vocabulary acquisition is of utmost importance in a child's education and life after school (Beck et al., 1982; Coyne et al., 2004; Cunningham \& Stanovich, 1997; National Reading Panel, 2000). If vocabulary proficiency is not acquired, a child faces sever educational implications in reading and reading comprehension (Beck \& McKeown, 2007; Juel \& Deffes, 2004). Vocabulary level differences can be detected as early as toddler age (Hart \& Risley, 1995), and can be attributed to differing socio-economic situations (Sharif et al. 2003).

Teachers and researchers alike have begun to see that many structured vocabulary programs do not do the job that they are intended to do. According to Blachowicz et al. (2006), in order to teach individual words, teachers have begun to put pieces together to make up their own vocabulary instruction. Still, say the authors, the teachers are wondering how they can effectively teach vocabulary for the good of their students. The authors developed a list of components of what a good, strong vocabulary program should encompass. First, the vocabulary program should take place in an environment that is word and language rich for the students. Second, it should include the teaching of selected words, with multiple exposures, repeated use, and different teaching strategies for each word. Third, it should include word learning strategies and word practice in 
many different ways that include the student and independent word practice. These components align with the components of Graves (2006), and the current study.

To develop an environment that is word and language rich, Beck et al. (2002) suggest that teachers should model sophisticated word exchanges each day by engaging students in conversation using higher tier words. This also promotes teaching individual words, and fostering word consciousness. The students are then challenged to use the words themselves and to notice those words being used outside the classroom. Another activity suggested by the authors is for teachers to share and describe their favorite word to the class, and in this way promote word excitement and word consciousness (Beck et al., 2002, p. 116).

\section{Visualization}

Visualization means the formation of mental visual images, or the act or process of interpreting in visual terms, or putting into visual form (Webster's, 1997). Bustle (2004) felt that it was important to incorporate visualization into the classroom because, according to the author, students "understand that images have become a basic cultural phenomenon..." (Bustle, 2004, p. 416). She continued by saying that many teachers do not use visualization because the current trend in standardized testing has led to traditional approaches to teaching. Bustle stated that traditional approaches have minimalized the use of visualization as a teaching strategy, even though children are growing up in a world of visual representations, and education has not recognized the fact that children are bombarded everyday with visual images. According to Bustle, students need help learning to use those visual images to their advantage. Teachers need to educate students about the constant ways that visual representations invade their world, 
and teachers must embrace visual representations as a very useful tool for educating students (Bustle, 2004).

Bustle (2004) indicated that much was needed in the area of visualization as it pertained to learning, specifically that visual representations, which were excellent devices for generating meaning, were not often used in the current educational system, nor had they been well explored. She stated that visualizations were all around children every day, but were largely unused by our educational system as a powerful teaching strategy. Beck and McKeown (2001) also felt that pictures were an extremely important educational tool. "Children's reliance on pictures is easy to explain, and pictures closely represent what children are accustomed to encountering in the world around them. They can more readily derive information from pictures in comparison to text language." (Beck \& McKeown, 2001, p. 11).

In an article by Manning (2002), the author stressed that visualization in the form of mental imagery can improve students' comprehension. She noted that prior knowledge was important for use in formation of mental images. She felt that students could not build mental images of objects of which they had no prior knowledge. She stated that the students could talk about something that they were having trouble visualizing. In her study, students drew pictures of words, or representative illustrations of what students felt would remind them of the vocabulary word. If the students did not understand, they talked about the word with the teacher, and then, when they grasped the understanding of the word, they drew picture representations.

Brain research is receiving renewed attention in regard to reading. Questions being raised include questions about how learners learn, and how English language 
learners (ELs) learn. Mental imagery is being recognized as a tool in reading comprehension. Marzano, Pickering and Pollock (2001) stated that it has been established that showing students how to use imagery to illustrate information not only stimulates, but also elevates activity in the brain.

Canning-Wilson (2001) contended that there was a connection between language learning and use of visual cuing. The author found that visual cuing was a technique that helped students learn to read and comprehend. The current research study supports the idea that visual cuing is helpful to vocabulary learning.

Dual Coding is a theory posited by Pavio in 1971. His Dual Coding Hypothesis contended that the verbal and visual memory systems could function together to receive information. The theory emphasized the importance of nonverbal imagery as a way of thinking. It assumed that human cognition was made up of two separate systems that were highly specialized to process and encode language, events, and nonverbal happenings. The verbal system specialized in handling language. The nonverbal, or imagery area, specialized in encoding representations and the processing of the nonverbal objects and events. The important function of the nonverbal system included analyzing scenes and conjuring up mental images. The two systems were interconnected and could work independently or together. Dual Coding has a "conceptual peg" concept that enables the learner to use the key image conceptual peg to "hook" information for storage and retrieval. According to the Dual Coding Theory, sensory systems respond to their verbal and nonverbal stimuli and activate representations (Williams \& Dwyer, 2004). Vesely and Gryder (2007) felt that visualization worked well when combined with techniques in learning vocabulary. A picture acts much like a "peg" on which 
information is hung. The vocabulary word can more easily be retrieved from memory using the conceptual peg. Students can be trained to use this conceptual peg more often, through continued use of a visualization technique. When the verbal and visual systems work together, students are more likely to learn vocabulary and start building a larger and stronger store of vocabulary words.

Vesley and Gryder (2007) believed in teaching visual imagery as a strategy for vocabulary learning, and did a research study on whether teachers and teacher candidates used proven strategies when teaching vocabulary, and if they used visualization as one of their strategies. They found that many teachers did not use proven strategies if they felt uncomfortable using a new strategy. The researchers found that if a teacher was given information on how to teach a new strategy and given experience using it, then his comfort level would rise and he would then commit to using that strategy. The authors stated that "visual imagery, as a meta-cognitive tool, assists students and teachers in assessing understanding of vocabulary knowledge, concept acquisition, and basic skills mastery.” (Vesley \& Gryder, 2007, p. 51).

Vesley and Gryder gave credit to Blachowicz and Fisher (2000) for posing four main principles of vocabulary instruction. They included first, that students should personalize word learning, second that students should be immersed in words all day, and in numerous forms, third, that students need repeated exposure to words and word use, and fourth, that students should be active participants and should make connections to new vocabulary with what they already know. The authors felt that linking words to visual images was a strategy that fulfilled three of the four principles listed by Blachowicz and Fisher. 
According to Vesley and Gryder, visual imagery, as it was conceptualized by their study, was supported by Pavio's Theory of Dual Coding. Pavio's theory found that verbal and nonverbal information was represented and processed in different, but connected mental systems. Using visual imagery required a student to make word learning personal and build on prior knowledge to learn new vocabulary (Vesley \& Gryder, 2007).

A research study was conducted by Vesley and Gryder as to whether or not teachers and teacher candidates personally used and taught a strategy that is supported by research using visual imagery. Seventy-one teachers participated. Their study design was a simple, experimental, repeated measure, within subjects design. The independent variable was a teaching strategy, and the dependent variable was the number of vocabulary words remembered. The participants were given a list of paired words and told to memorize them in two minutes using a strategy they normally used to learn new vocabulary words. At the end of two minutes, each participant was asked to write down the word that was the other half of the pair of words that was learned. One of the pair was pronounced by a researcher. Directions for the second list included using mental imagery to learn new vocabulary words. At the end of two minutes, the researcher repeated the process of calling out one of the words in a pair, and the participants were to write down the other word. After three hours, the same tests were repeated. At the end of the activity, the participants discussed how the visual imagery impacted their word learning. In each test, the visual imagery strategy test takers scored higher and had better recall. The authors stated that if teachers are unsure of a strategy, they will probably not use it, even if it has been shown to be effective in teaching vocabulary. When visual 
imagery was used to quickly learn vocabulary words, the results were better than when they did not use visualization.

Most of the participants reflected on the thought that they taught vocabulary by having their students use a dictionary and dictionary definitions. The authors stated that this method decontextualized strategies and did not help the students make relevant connections that are necessary to learning vocabulary. Visual imagery can help make connections and assist students in understanding words due to their own visual creations and representations (Vesley \& Gryder, 2007). According to the authors, visual imagery is in line with three of the four principles set down by Blachowicz and Fisher (2000). Those four principles included personalizing word learning, being immersed in words, having repeated exposure to those words, and making connections between what they know and the vocabulary they are learning. The three that are in line with visual imagery use are personalized word learning, immersion in words, and making connections between what they know and the vocabulary words they are learning.

Using visualization is one of the strategies that appears to be effective for EL students. Words are important to all students, including the great number of EL students that populate our schools. ELs come to school with differing degrees of English language skills, as well as differing degrees of their native language skills. The school systems need to find practical, effective strategies in order to assist the ELs. Educating these non-English speaking children is a challenging task. Teachers must use a multimodal instructional framework of strategies to reach these EL students.

Lapp, Flood, Moore and Nichols (2005) wrote a book about teaching literacy in a first grade classroom. According to the authors, classrooms will have children that speak 
more than one language and children with other languages as their native tongue, and assert that the language issue must be addressed. Their needs must be met in the area of vocabulary acquisition. The authors advocated using varied strategies to facilitate word learning. Some of the techniques included word sorts, which could be done as onset-andrime, and word-sort family games, which would include onset-and-rime patterned words. Picture dominoes were also discussed. Visualization was discussed as one of the strategies that was multi-modal and highly effective for ELs.

\section{Semantic Mapping}

Activating prior knowledge is an important aspect of vocabulary acquisition. It is a way for students to make connections from words they know to words they do not know (Rupley, Logan, \& Nichols, 1999). Webbing maps are useful when used to incorporate prior knowledge and to share that knowledge. A semantic web is a web-like

picture. Students need time to cement the associations they have with words and prior knowledge in order to increase vocabulary. The Texas Reading Initiative (2002) indicated that discussion, along with webbing was especially helpful for students learning words. A discussion caused students to rehearse an answer that they might give if called upon by the teacher, therefore helping the students learn each word. The idea that a student would silently rehearse an answer to a discussion question enhanced and underlined the need for discussion of vocabulary words and their meanings to augment learning. Discussion is a key component of the current study.

Two ideas for teaching word learning strategies mentioned by Blachowicz et al. (2006) were semantic mapping and active engagement. Active engagement ranged from word games to puzzles. Semantic mapping was described as the words being displayed 
graphically, showing the relationship among the words with a central concept. Semantic mapping was a way for students to graphically make connections to vocabulary words, therefore making the word learning more visual. The authors felt that the existing research in that area stressed that there was a connection between learning vocabulary words and using semantic connections to those words. According to the authors, instruction that combined information on the definition, as well as other active manipulation of the words, is more helpful and productive than instruction of definition by itself (Beck \& McKeown, 2001; Blachowicz et al., 2006). Visualization strategies such as picture drawing, semantic mapping, and manipulation of words assist the students with multi-modal learning.

Concept mapping, another form of semantic mapping, is a technique that clarifies an idea and depicts a relationship. Concept mapping provides a visual cue, something concrete, on which a child can concentrate. When a child uses a concept map, or a visual cue that he has constructed, learning becomes an interactive process. Using a concept map that the child has constructed helps insure that prior knowledge is activated. Prior knowledge is important for learning to take place. Children build upon their prior knowledge and widen their knowledge base.

\section{Onset-and-Rime}

Analogy-based phonics is the study of words using same sounding endings. This is onset-and-rime, a type of analogy-based phonics study. It involves an onset, the initial position, and a rime, which is the ending of the word. White (2005) stated that analogybased phonics teaches students to use known words to decode unknown words. Analogybased phonics is systematic and teaches a planned pattern of phonic elements in a 
sequence. One such phonic element is common spelling patterns. Teachers train students to stop when they come to a word they do not know and think of a word they do know that is like the word they do not know. This works like onset-and-rime. Students can substitute a beginning consonant in a word that they do know to figure out a word that they do not know. Onset-and-rime words, like analogy-based words, have the same spelling patterns.

White (2005) stated that Cunningham and Cunningham (2002) wrote that there were three principles behind an analogy-based phonics program. The three principles were active engagement, multi-sensory and multi-level learning emphasizing transfer, and cognitive clarity. This gives credence to including visualization with the use of onset-and-rime when learning vocabulary.

White (2005) did a study on analogy-based phonics. He gave second-grade teachers 150 analogy-based lessons to use over the course of a school year. The lessons were designed to help develop the skills of low and normally achieving students and their ability to decode by analogy. White's designed lessons provided for sequential teaching of phonic elements, teacher modeling of strategic use of an analogy decoding strategy, and practice using the analogy decoding strategy. The lessons were taught in conjunction with a comprehension-based reading program. White's results showed a positive relationship between the number of lessons taught and the progress made on standardized tests of word reading and reading comprehension. The students also showed gains on additional posttests of the base words taught in the program. According to White, the systematic teaching of analogy-based phonics illustrates the feasibility of using this kind of program. 
Jalongo (2007) stated in her book that one way children can maximize their phonics and vocabulary learning was by learning and understanding onset-and-rime. Onset-and-rime is often referred to as word families. Children learn that by changing the first letter of a word, or the onset, they can form new words. If the phonic elements are taught directly, as in onset-and-rime, then students will be able to recognize and learn words. This study couples student-generated pictures of onset-and-rime patterned vocabulary words, and story read-alouds with discussion, to create a strong, multimodal framework of strategies designed to help low and normally achieving first-grade students.

\section{Read-Alouds With Discussion}

Reading aloud to students has been one of the foundations of literacy for a century (Brabham \& Lynch-Brown, 2002). Opitz and Rasinski discussed its benefits in 1998. By listening to stories, students could make connections between words and print, and hear the different forms of language. Students could also make cultural connections through exposure to books read aloud to them. Research, coupled with this information, deems it important for teachers to read aloud to students every day (Brabham \& Lynch-Brown, 2002).

Brabham and Lynch-Brown (2002) asserted that students made substantial vocabulary gains from stories being read aloud to them. They contended that read-alouds were a powerful literacy tool that worked well with vocabulary acquisition, especially in conjunction with discussion during reading. The authors stated that read-alouds could help students achieve substantial gains in vocabulary acquisition, as opposed to students who do not participate in read-alouds. Brabham and Lynch-Brown (2002) also suggested that vocabulary gains could lead to comprehension gains. 
Graves (2006) stated that one way to build students' vocabularies was to immerse them in a rich range of language and word experiences. This could be done through listening, speaking, and reading. Adams (1990) felt that reading aloud to students helped promote their early literacy development. The National Reading Panel (2000) said that there was a high correlation between vocabulary knowledge and comprehension (pp. 497) when students heard books read to them.

Baumann (2009) also stated that reader-listener interaction during read-alouds facilitated vocabulary attainment. A study by Biemiller and Boote (2006) looked at the effects of teachers' explanation of words during multiple read-alouds to kindergarten, first and second-grade students. The children with the multiple word exposures and explanations showed pretest / posttest gains for words explained.

\section{English Learners}

Word walls are a great place to concentrate on when creating a print rich classroom. Labeling everything in the younger grades helps promote a print rich environment, as well as attaching a word to an object, which is especially helpful to EL students. The print rich environment is made even more effective when teachers incorporate word wall activities into their daily plans. Word wall activities can include visual and kinesthetic word practice, making word learning fun and interactive.

Canning-Wilson (2001) found that there was a connection between language learning and visual cuing, which could benefit English language learners. Realia is a term used to describe real objects that represent words. Students can see and feel a real object such as a vase, as the teacher passes around a vase and spells the word vase. Realia enables the student to form a mental picture of a vase in his brain. The 
visualization technique is useful for all students, but especially helpful for EL students while learning new words in a new language.

Weber and Longhi-Chirlin (2001) also studied the use of visuals with EL students. They advocated the use of integrated techniques in the classroom withL students, including the use of visuals. The researchers followed two Puerto Rican students and the problems they faced as Spanish speakers in an American classroom. The researchers found that both children improved academically using integrated techniques, and a large part of their learning experiences were in the mainstream classroom.

Blachowicz et al. (2006) revealed that a command of the most basic and most frequently used words in the English language was a starting place for EL students. Word learning for outside the school environment is different than word learning for academics. Academic words are more complicated and especially hard for EL students to grasp. Academic words and a varied vocabulary are a necessity for school success for EL students.

Jalongo (2007) also believed that EL students were in need of more direct vocabulary instruction. When English vocabulary at home was limited, as in the homes of EL students, picture books could provide visual, as well as verbal information. Pictures, she stated, were a very effective tool to use with EL students, and provided support for those students. Pictures promote the use of visualization techniques.

Uberti, Scruggs, and Mastropieri (2003) did a study on vocabulary learning and the key-word system. They stated that children with learning disabilities were in inclusive classrooms more and more. Those students need strategies to use in order to 
learn vocabulary. They set up a research project teaching vocabulary using the keyword system in conjunction with mnemonic instruction. The authors planned to read a book to the students, who were between eight and 10 years old. They formed three groups with all groups receiving a set of vocabulary words from the story. One group received only definitions with the vocabulary list. Another group received definitions and a representational picture which was non-mnemonic. The third group received the definitions, the keyword and a picture related to the word. The authors wanted to see how the study would influence vocabulary learning. All groups were given a pretest. The study showed that students without disabilities benefited from the keyword system, and those students with disabilities benefited greatly from the system.

\section{Assessment}

According to Blachowicz et al. (2006), there were limitations using the conventional approach to vocabulary assessment. They stated that conventional assessments may not be able to measure the gradualness of word learning. They said that measuring word learning was still the same as it was 75 years ago, and that it points to a "clear vacuum in research and one that should be addressed in a more sensitive way." (Blachowicz et al., 2006, p. 532). They stated that more research was needed in the area of the understanding of meta-cognition in relation to learning and instructing vocabulary.

Moats (2000) warned that the use of whole language in a classroom was not effective for low socio-economic, urban and minority students. According to Moats, the use of miscue analysis and running records as assessments was still widely used. Both were mostly whole language tools. She discussed the idea that a running record and word miscue analysis were not reliable, and wasted the teacher's time. This was due to the fact 
that one teacher would not necessarily record the errors the same as another teacher, and students were not likely to show the same pattern of miscues from day to day. Moats went on to say that the relationship between miscue patterns and reading achievement levels has not lead to any significant information and correlation. The author believed that teaching reading should be research-based. The teaching of reading should employ phonemic awareness, alphabetic skills, reading fluency, decoding skills, vocabulary and comprehension. She advocated these basic skills being taught rather than using the whole language approach. She concluded by reiterating that the students most vulnerable to the whole language failure were the urban, low socio-economic, and minority students. These students were the most impacted and needed to be taught skills and strategies that would actually facilitate vocabulary acquisition and reading comprehension.

\section{Summary}

This review of the literature presented a summary of the reasons for researching visualization, student-generated pictures of onset-and-rime patterned vocabulary, and story read-alouds with discussion using those words, to facilitate diverse first-graders' acquisition of weekly vocabulary words and comprehension. Students from low socioeconomic backgrounds are entering school with vocabulary levels well below middle and upper socio-economic background students. The problem is currently not being successfully ameliorated, and teachers need assistance locating and applying a multimodal instructional framework of strategies that work effectively for diverse, low socio-economic students.

Cunningham (2001) appeared to be frustrated by the fact that many educational pundits thought that there were universal approaches to teaching reading and that a "one 
size fits all" approach would work. He stated that they did not take into account the fact that all students were different, and that this might have an impact on the situation. There were different variables, such as socio-economic status, location, educational level of the parents, living conditions, and the different intelligences that all came into play as a student was learning to read. Therefore, there was not a "one size fits all" magic bullet. Cunningham was of the opinion that due to the differing variables, the degree of motivation and prior background knowledge, it made sense that different approaches work for different students and situations. He added that the National Reading Panel reminded him of Rip Van Winkle, when it acted as if it woke up after 20 years of sleep, and then did just what Congress told it to do.

White's (2005) research on analogy-based phonics used onset-and-rime with second grade students. He alleged at the beginning of his research article findings that, "Despite several decades of research, I know of no published study of an analogy-based phonics program that was implemented by regular classroom teachers. This study fills that gap." (p. 237). Analogy-based phonics is like onset-and-rime. The ending word patterns are taught and the initial consonant is changed to make new words. The current study is also being conducted to add to the knowledge base of classroom teachers.

Previous study results suggest that students benefit and make larger gains in vocabulary acquisition when they play an active part in the learning of each word. Participation on the part of each student is a vital ingredient to word learning and vocabulary enlargement. Many of the studies cited have shown that when the children take advantage of active involvement in learning vocabulary, vocabulary is acquired. Research supports the concept that word learning is enhanced by active participation on 
the part of the students. It is agreed upon that teachers should incorporate teaching vocabulary in multi-modal ways using multiple strategies, with multiple exposures to each word, and active engagement on the part of the students.

Active participation on the part of the student is an important major factor in vocabulary attainment success for urban, low socio-economic students. Students should no longer be passive learners in the area of their vocabulary procurement (Beck \& McKeown, 2007). Teachers need to be made aware of the advances in vocabulary acquisition strategies in order to give their students the best possible chance at a productive school career.

Graves (2006) put vocabulary instruction into perspective with his fourcomponent framework for comprehensive vocabulary instruction. Other researchers echoed Graves' framework components by providing rich and varied language experiences, teaching individual words, teaching word learning strategies, and fostering word consciousness. Hart, Berringer, \& Abbott (1997) also believed that "combining methods of vocabulary acquisition may be more effective than using only a single method" (p. 3).

In conclusion, there is evidence to suggest that using a multimodal instructional framework of strategies, modeled after Graves' four-component comprehensive vocabulary instruction, using multiple strategies, will help enable students in low socioeconomic circumstances to acquire the vocabulary needed to improve comprehension. This study will address these issues using visualization, student-generated pictures of onset-and-rime patterned vocabulary, and read-alouds with discussion in order to enhance diverse first-grade students' acquisition of vocabulary words and story comprehension. 


\section{CHAPTER III}

\section{METHODS}

\section{Purpose of the Study}

This study was designed to study the effect of using a multimodal framework of instructional strategies incorporating visualization, student-generated pictures of onsetand-rime patterned vocabulary with discussion focusing on those words, and story readalouds using those words to improve first-grade students' comprehension of weekly vocabulary word lists and stories. Chapter 3 presents the research questions and the research hypotheses, describes the research design, the research setting, the sample, the sampling, the instruments, the variables, the procedure, the data collection, and methods.

\section{Research Questions}

1. Will visualization, student-generated pictures for onset-and-rime- patterned vocabulary, and story read-alouds including those words, and discussion focusing on those words, improve first-grade students' comprehension of weekly vocabulary lists and stories, as well as FAIR Comprehension and FAIR Vocabulary scores, compared to a comparison group receiving traditional instruction?

2. Will comprehension and vocabulary gains for first grade students using visualization, student-generated pictures for onset-and-rime- patterned vocabulary, and story read-alouds including those words, and discussion focusing on those words, and a comparison group receiving traditional instruction differ between EL students in the treatment group and EL students in the comparison group? 


\section{Hypotheses}

1. If visualization, in conjunction with onset-and-rime patterned vocabulary words, and story read-alouds with discussion is used with first-grade students, it will improve scores in comprehension and vocabulary more than scores for the comparison group, as measured by the FAIR Comprehension, FAIR Vocabulary, Treasures Comprehension, and Treasures Vocabulary tests.

2. If visualization, in conjunction with onset-and-rime patterned vocabulary words, and story read-alouds with discussion is used with first grade students, it will improve treatment group EL comprehension and vocabulary scores more than comparison group EL scores, as measured by the FAIR Comprehension, FAIR Vocabulary, Treasures Comprehension, and Treasures Vocabulary tests.

\section{Research Design}

The researcher employed a quasi-experimental design (Newman, Newman, Brown \& McNeely, 2006). Students in both groups were pre and posttested on the Florida Assessments for Instruction in Reading (FAIR) Comprehension, FAIR Vocabulary, and the Treasures Vocabulary. During treatment, students in both groups took 8 weekly Macmillan/McGraw-Hill Treasures reading comprehension tests, and 8 weekly Macmillan/McGraw-Hill Treasures vocabulary tests.

\section{Research Setting}

This study took place at an elementary school located in a large school district in the southeastern part of the United States. The school district was home to an eclectic diversity of ethnic and racial minorities. The racial/ethnic ratio for the school district/county was White, 50.81\%, Black, 40.26\%, Hispanic, 29.04\%, Asian, 3.65\%, 
Native American or Native Alaskan, 1.68\%, Native Hawaiian or Pacific Islander, 0.13\%, and Multiracial, 3.47\%. This elementary school had a population of 648 students. The ethnic ratio for the elementary school was White, $8.95 \%$, Black, $55.0 \%$, Hispanic, $34.1 \%$, Asian, $0.61 \%$, Native American or Native Indian, 0.30\%, Native Hawaiian or Pacific Islander, $0 \%$. Of the 648 students, $95 \%$ qualified for free or reduced meals. The school was classified as a Title 1 school, which meant that it received extra funding from the state to help bolster academic gains of the lowest performing students.

\section{Sample}

Participants for this research study included 69 first grade students ranging in age from 5 years, 6 months old to 8 years old. All of the students came from low socioeconomic homes and received free or reduced meals. There were two groups of students. One group of 34 students comprised the treatment group, which contained 20 EL students, and 14 native English speakers. The second group of 35 students comprised the comparison group, which contained 19 EL students and 16 native English speakers. Each group consisted of two first-grade classrooms with approximately 17 students per class.

Table 1 shows the number of students participating in each class, each group, and shows whether they were native speakers or ELs.

Table 1

Frequencies of Students Participating in the Study by Treatment, Class and EL Status

Groups Native ELs Total
Speakers

Treatment Class 1

Treatment Class 2

Comparison Class 1

13

1

15

4

17

Comparison Class 2

$\begin{array}{lr}1 & 16\end{array}$

18

17 


\section{Sampling}

Because the classes were pre-determined, stratified random sampling was not used to select the participants. Teachers were selected based on their willingness to participate in the implementation of the study. Four teachers took part in the study. The researcher was one of the teachers taking part in the study and taught Treatment Class 1.

\section{Instruments}

Instruments used included story comprehension and vocabulary tests from the adopted school district curriculum reading series, Treasures, by Macmillan/McGrawHill. The Florida Assessments for Instruction in Reading (FAIR) was used as the pre and posttest, which tests both comprehension and vocabulary (Florida Center for Reading Research, 2010). FAIR reliability was evaluated by Buros Center for Testing (2010). Buros reported internal consistency estimates above 0.85 . The test met established criterion for validity. The test developers established a target goal of $85 \%$ negative predictive power, meaning that $85 \%$ of students classified according to their probability of reading success (PRS) or their Florida Comprehensive Achievement Test (FCAT) success probability (FSP) scores as not-at-risk would also be not-at-risk on the outcome measure, either the Stanford Achievement Test (SAT-10), or the FCAT. The test met the established criterion outright. In first grade, negative predictive power approached or surpassed $90 \%$. 


\section{Variables}

The independent and dependent variables were as follows:

Independent variable: The independent variable was educational treatment with two values; a multimodal framework of strategy instruction for the treatment group and traditional instruction for the comparison group.

Dependent variables: The dependent variables included the FAIR Comprehension and the FAIR Vocabulary scores, the Treasures Comprehension 8 weekly reading comprehension test scores, and Treasures 8 weekly vocabulary test scores.

\section{Procedures}

Teacher training took place for both the treatment group teachers and the comparison group teachers before the study began. Teachers were trained by the researcher separately by treatment group or comparison group for 20 minutes each group for five days on how to implement the procedure. The study procedure for both groups lasted for 20 minutes per day each week during reading group. The school Reading Specialist attended all trainings. A procedural manual was given to each teacher for referral. The procedural manual was written by the researcher. The researcher observed each teacher once a week on different days and at different times. The observer entered the classrooms and observed the teachers conducting the class according to the procedural manual. The school Reading Specialist monitored the teachers for fidelity of treatment on a weekly basis on different days and at different times. She also came into a room unannounced and observed what activities were taking place with respect to the study. With regard to fidelity, teachers were to follow the procedural manual as written and discussed. 
The treatment group received the intervention: a multimodal strategy which included visualization, onset-and-rime words, read-alouds, and discussion for the treatment group who were being administered the multimodal strategy. Visualization was in the form of student-generated pictures of vocabulary words. The six vocabulary words for the week consisted of onset-and-rime patterned words, and were the same words that the comparison group used. The story of the week, which was read by both groups, also used the same vocabulary words. Both the stories and the vocabulary words came from the basal series, Treasures for First Grade. The teachers read the weekly stories aloud and conducted discussion about the stories, emphasizing the vocabulary words through game playing.

The comparison group received traditional instruction with students copying the vocabulary words into their agendas on Monday. The words were the same onset-andrime words that the treatment group were studying and came directly from the story of the week. The teachers also conducted read-alouds with discussion for the story of the week, but did not emphasize the vocabulary words through discussion or game playing.

\section{Treatment Group Procedure}

Each day, the reading group lasted for 20 minutes. Each Monday, for the treatment group, 10 words were written on the board for the week. Six of the words were onset-and-rime words, two of the words were review words from the week before, and two of the words were high frequency words. Only the onset-and-rime words were looked at in this study. All six words were defined for the students. A picture or an object was displayed for each of the six onset-and-rime words, in order to promote the use of visualization. The teacher modeled the use of the words spoken aloud in 
sentences. The students printed each of the six words on separate 5 " 8 " index cards, and drew a picture of that word on the back to incorporate visualization. The cards were hole-punched and stored on a ring in an index card box. In small reading groups, the teacher directed students to think of a sentence for each vocabulary word. The teacher picked one of the sentences for each word and wrote it on the board. The sentence was then copied by the students onto the appropriate index cards. Each student had a separate card with a self-drawn picture and a sentence for each of the onset-and-rime words.

On Tuesday during small reading groups, the teacher read aloud the story from the decodable book containing the vocabulary words. A decodable book is considered a low leveled book that allows students to use decoding strategies. The students had their vocabulary index cards spread out in front of them. When they heard a vocabulary word, they put their finger on it. The teacher then had the students take a picture walk (look at the pictures) through the main story for the week. Students discussed what they thought would happen in the story. The students again had their six cards spread out on their desks. When the students heard one of the vocabulary words, they pointed to that index card. Discussion was held about each word as they appeared in the story.

On Wednesday in small reading groups, the students listened to the teacher read the leveled book. They pointed to their word cards in front of them as they listened to the story. The teacher then reread the main story with the students pointing again to their word cards if they heard a vocabulary word in the story. Students were directed to discuss their favorite part.

On Thursday, students reread the main story with teacher assistance. Each student took a turn reading. Then the teacher read the main story again. When she came 
to one of the vocabulary words, she said, "I am thinking of a word that means (teacher gave a brief description of the word). She directed the students to point to one of their cards if they knew the word. Each student was then asked to create a sentence using one of the vocabulary words.

On Friday, all students took both a story comprehension and vocabulary test. Testing for both the vocabulary and the story took 20 minutes.

\section{Comparison Group Procedure}

Each day the reading group lasted 20 minutes. On Monday for the comparison group, students copied the ten vocabulary words into their school agendas. The teacher read and explained each vocabulary word to the students. Students were asked to use a vocabulary word in a sentence to be said aloud to the class.

On Tuesday in small groups, the students read the decodable book aloud with teacher assistance and discussed it. The decodable book is designed to help the students sound out words they do not know, including the weekly vocabulary words. The teacher then had students take a picture walk through the main story. The students then read the leveled book with teacher assistance.

On Wednesday in small group, the teacher read the main story with students echo reading (reading with her as she read). Students discussed the story with teacher assistance. Students also talked about concepts of print as they appeared in the story.

On Thursday in small group, students reread the main story, along with the teacher, with each student taking a turn reading. Students reread the leveled text and reviewed concepts of print. 
On Friday, all the comparison group students took the same vocabulary and story comprehension tests as the treatment group students. The vocabulary and comprehension tests took 20 minutes.

\section{Data Collection}

Data collection occurred over 14 weeks, with the exception of the FAIR Vocabulary posttest (Table 2). At pretest (weeks 1 and 2), students were given the FAIR 1 Comprehension Test, as well as the FAIR 1 Vocabulary Test. This process took two weeks because only a limited number of students could be tested each day due to school day constraints. Then, each week for 8 weeks $(3-10)$ the Treasures Reading Series was used to measure story comprehension and vocabulary associated with the weekly stories. At weeks 11 and 12, students were given the FAIR 2 Comprehension posttest. However, the posttest for the FAIR 3 Vocabulary Test was administered 8 weeks after that. This was due to the fact that the State of Florida only approves of administering this test

during specific windows of time during the year, and the vocabulary test section was not offered in FAIR 2. 
Table 2

Data Collection

\begin{tabular}{cl}
\hline Week & \\
\hline 1 & FAIR 1 Comprehension and Vocabulary Tests \\
2 & FAIR 1 Comprehension and Vocabulary Tests \\
3 & Treasures Story 1 Comprehension and Vocabulary Tests \\
4 & Treasures Story 2 Comprehension and Vocabulary Tests \\
5 & Treasures Story 3 Comprehension and Vocabulary Tests \\
6 & Treasures Story 4 Comprehension and Vocabulary Tests \\
7 & Treasures Story 5 Comprehension and Vocabulary Tests \\
8 & Treasures Story 6 Comprehension and Vocabulary Tests \\
9 & Treasures Story 7 Comprehension and Vocabulary Tests \\
10 & Treasures Story 8 Comprehension and Vocabulary Tests \\
11 & FAIR 2 Comprehension Tests \\
12 & FAIR 2 Comprehension Tests \\
\hline
\end{tabular}

The 48 vocabulary words from the eight Treasures Reading Series stories were also used as a pre and post vocabulary test. With six words a week for 8 weeks, the researcher chose three words each week for the pretest, and three words each week for the post test. As indicated above, the treatment group consisted of two first grade classes. One of the treatment group classes used words 1 to 24 (List A), while the other treatment group class used words 25 to 48 (List B) for the pretest. The comparison group also 
consisted of two first grade classes and did the same. After the eight weeks, each class took the other half of the vocabulary words as the posttest.

\section{Statistical Analysis}

The statistical tests for the hypothesis of research question one were one-way analyses of covariance (ANCOVAs) to determine if FAIR Comprehension, FAIR Vocabulary, and Treasures Vocabulary gains were significantly different by group (treatment, comparison). The statistical tests for the hypothesis of research question two were two-way ANCOVAs to determine if FAIR Comprehension, FAIR Vocabulary, and Treasures Vocabulary gains differed by EL status. The .05 level of significance was used for all tests. A power analysis was done for an $N=69, \alpha=.05$, and a medium to large effect size $\eta^{2}=.12$ and power was found to be $82 \%$ (GPower 3.1 ). Thus, the sample size was sufficient to test the hypotheses.

\section{Summary}

In this research study, 69 first-grade students in a low socio-economic urban school participated in an eight week vocabulary intervention program. Four first-grade teachers taught the daily twenty minute lessons. A multimodal instructional technique, student-generated pictures of onset-and-rime patterned vocabulary, and story read-alouds using those words coupled with discussion incorporating those words, was applied to test whether it would improve first-grade students' vocabulary and story comprehension. 


\section{CHAPTER IV}

\section{RESULTS}

The purpose of this study was to investigate the benefits of using a multimodal instructional framework of strategies to improve diverse first-graders' vocabulary and comprehension. Visualization, onset and rime, and story read-alouds with discussion were combined to facilitate the desired outcome of improved vocabulary and comprehension in both native speakers and English learners (ELs). This study looked at the benefits to classes consisting of both native speakers and ELs. Additionally, the study investigated the differences in results using this multimodal instructional framework of strategies between the ELs in the treatment group and in the comparison group.

Students from an inner city school in the first grade took part in this study. All students were between the ages of 5 years, 6 months old and 8 years old. Two classes were designated as the treatment group and two classes were designated as the comparison group. One class in each of the groups was primarily made up of ELs. The treatment group consisted of 34 students, 20 EL students and 14 native English speakers. The comparison group consisted of 35 students, 19 EL students and 16 native English speakers. There was no significant difference between the two groups in percentages of ELs, $\chi 2(1, \mathrm{~N}=69)=0.15, p=.704$, (Table 3). Fifty-nine percent of the treatment group and $54 \%$ of the comparison group were ELs. 
Table 3

English Learner Status by Group

\begin{tabular}{lccccc}
\hline EL Status & $\begin{array}{l}\text { Treatment } \\
(\mathrm{n}=34)\end{array}$ & Frequency & $\%$ & $\begin{array}{l}\text { Comparison } \\
(\mathrm{n}=35)\end{array}$ & $p$ value \\
\hline EL & 20 & 58.8 & 19 & 54.3 & .704 \\
Non-EL & 14 & 41.2 & 16 & 45.7 & \\
\hline
\end{tabular}

Table 3 shows the percentage of EL and non-EL students in both the treatment group and the comparison group. The treatment group contained 34 students, with 20 being ELs. The comparison group contained 35 students, with 19 being ELs. The frequency of EL per group was considered to be even, with $59 \%$ of the treatment group ELs, and $54 \%$ of the comparison group ELs.

Next, the two groups were compared at pretest on the FAIR Comprehension, FAIR Vocabulary, and Treasures Vocabulary to determine whether the groups were similar at pretest, since the groups were pre-determined and no randomization was possible. Table 4 shows that there were no significant differences between the treatment and comparison groups on any of the three measures at pretest, $p \mathrm{~s}>.05$. 
Table 4

Pretest Means (SDs) of the FAIR Comprehension, FAIR Vocabulary, and the Treasures

Vocabulary

Variable

$\begin{array}{lll}\frac{\text { Treatment }}{(n=34)} & & \text { Comparison } \\ \text { Mean } & \text { Mean } & \end{array}$

(SD)

(SD)

FAIR Comprehension

53.88

(25.72)

58.00

.535

(28.66)

FAIR Vocabulary

29.32

(18.41)

29.18

(18.13)

.974

8.44

$(6.72)$

10.29

(7.43)

Note. Ranges of FAIR Comprehension 1-100, FAIR Vocabulary 1-100, Treasures Vocabulary 0-24.

The statistical tests for the hypothesis of Research Question 1 were one-way analyses of covariance (ANCOVAs) to determine if Florida Assessments for Instruction in Reading (FAIR) Comprehension, FAIR Vocabulary, and Treasures Vocabulary gains were significantly different by group (treatment, comparison). The statistical tests for the hypothesis of Research Question 2 were two-way ANCOVAs to determine if FAIR Comprehension, FAIR Vocabulary, and Treasures Vocabulary gains differed by EL status. The .05 level of significance was used for all tests. IBM SPSS v. 21 was used for all statistical analysis.

\section{Results for Research Question 1}

Research Question 1 asked if using a multimodal strategy approach would show greater improvement in reading comprehension and vocabulary acquisition by students in 
the treatment group than students in the comparison group as measured by the FAIR and Treasures. There was a significant difference in adjusted FAIR Comprehension means by group, $F(1,65)=6.79, p=.011, \eta^{2}=.10$, (Table 5). The treatment mean gain score on FAIR Comprehension (adj $M=5.14$ ) was significantly higher than that of the comparison group (adj $M=-8.26$ ). Students in the treatment group scored significantly higher on the FAIR Comprehension posttest than the students in the comparison group.

Table 5

Observed and Adjusted Mean Gains for FAIR Comprehension, FAIR Vocabulary, and Treasures Vocabulary by Group

\begin{tabular}{|c|c|c|c|c|c|}
\hline \multirow[t]{3}{*}{ Test } & \multicolumn{2}{|l|}{ Treatment } & \multicolumn{2}{|l|}{ Comparison } & \multirow[t]{2}{*}{$p$ value } \\
\hline & Observed & Adjusted & Observed & Adjusted & \\
\hline & $\begin{array}{c}M \\
(\mathrm{SE})\end{array}$ & $\begin{array}{c}M \\
(\mathrm{SE})\end{array}$ & $\begin{array}{c}M \\
(\mathrm{SE})\end{array}$ & $\begin{array}{c}M \\
(\mathrm{SE})\end{array}$ & \\
\hline $\begin{array}{l}\text { FAIR } \\
\text { Comprehension }\end{array}$ & $\begin{array}{c}5.12 \\
(3.90)\end{array}$ & $\begin{array}{c}5.14 \\
(3.63)\end{array}$ & $\begin{array}{l}-8.24^{*} \\
(3.27)\end{array}$ & $\begin{array}{l}-8.26^{*} \\
(3.63)\end{array}$ & $.011 *$ \\
\hline $\begin{array}{l}\text { FAIR } \\
\text { Vocabulary }\end{array}$ & $\begin{array}{l}5.85 * * \\
(2.04)\end{array}$ & $\begin{array}{l}5.85 * * \\
(2.05)\end{array}$ & $\begin{array}{l}17.97 * * \\
(2.04)\end{array}$ & $\begin{array}{c}17.97 * * \\
(2.05)\end{array}$ & $.001 * *$ \\
\hline $\begin{array}{l}\text { Treasures } \\
\text { Vocabulary }\end{array}$ & $\begin{array}{l}8.53 * * \\
(0.91)\end{array}$ & $\begin{array}{l}8.26^{* *} \\
(0.77)\end{array}$ & $\begin{array}{l}6.94 * * \\
(0.76)\end{array}$ & $\begin{array}{r}7.21^{*} \\
(0.76)\end{array}$ & .340 \\
\hline
\end{tabular}

${ }^{*} p<.05, * * p<.01$.

Note. Individual means are tested against zero. Adjusted mean gains are evaluated at pretest mean scores.

Additional tests indicated that the treatment FAIR Comprehension did not significantly increase from pre to post, but the comparison FAIR Comprehension significantly decreased from pre to post as shown in Figure 1. 


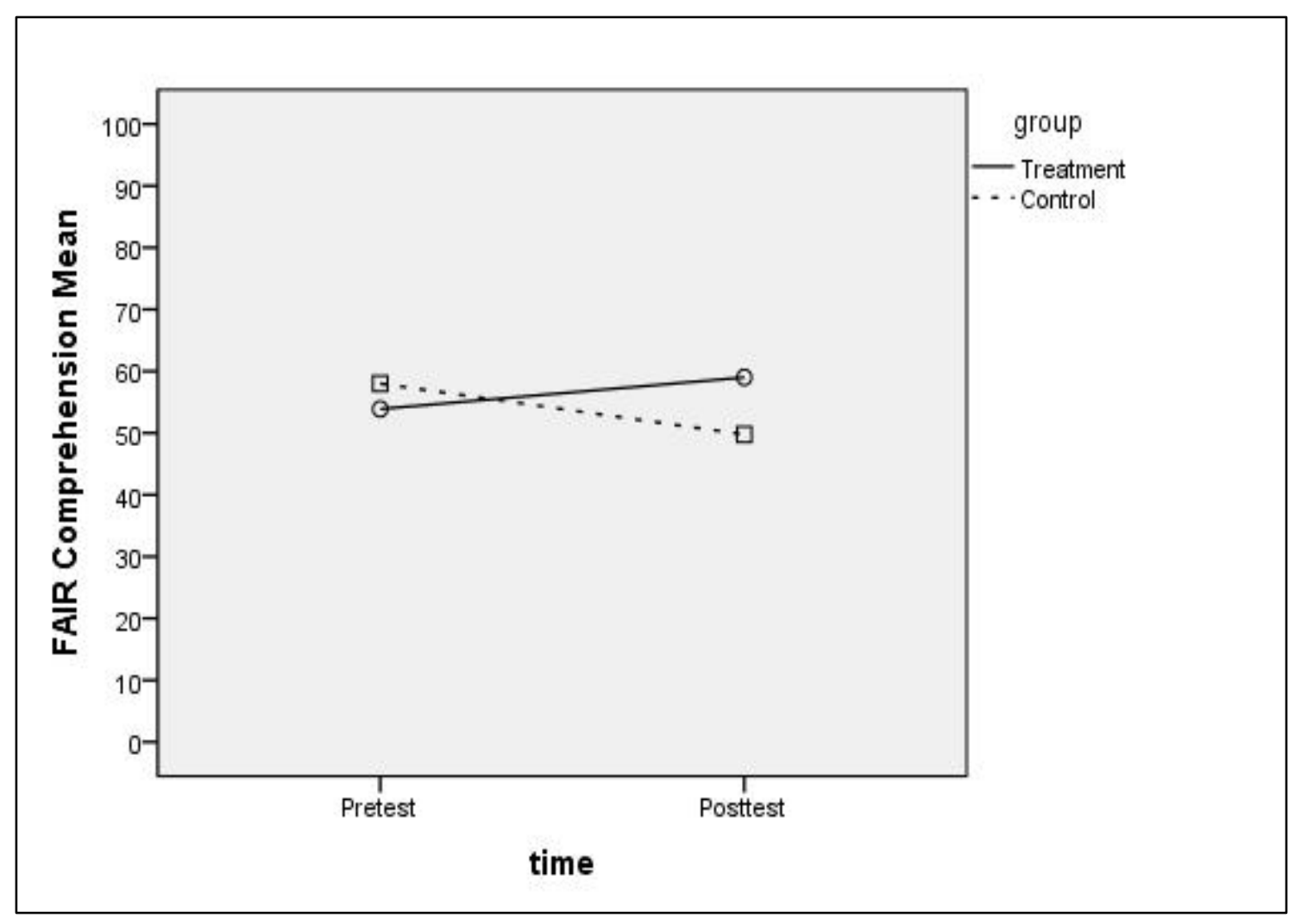

Figure 1. Pre and Adjusted Post FAIR Comprehension Means by Group

There was a significant difference in adjusted FAIR Vocabulary means by group, $F(1,65)=17.40, p<.001, \eta^{2}=.21$. However, the treatment mean gain score $(\operatorname{adj} M=$ 5.85) was significantly lower than that for the comparison group (adj $M=17.97$ ).

Students in the treatment group did not improve on the FAIR Vocabulary as much as the comparison group did, as shown in Figure 2. Additional tests indicated that the FAIR Vocabulary means increased significantly for both groups. Note that the FAIR Vocabulary posttest, consisting of words that were not part of the Treasures vocabulary, was administered 8 weeks after the intervention was completed. 


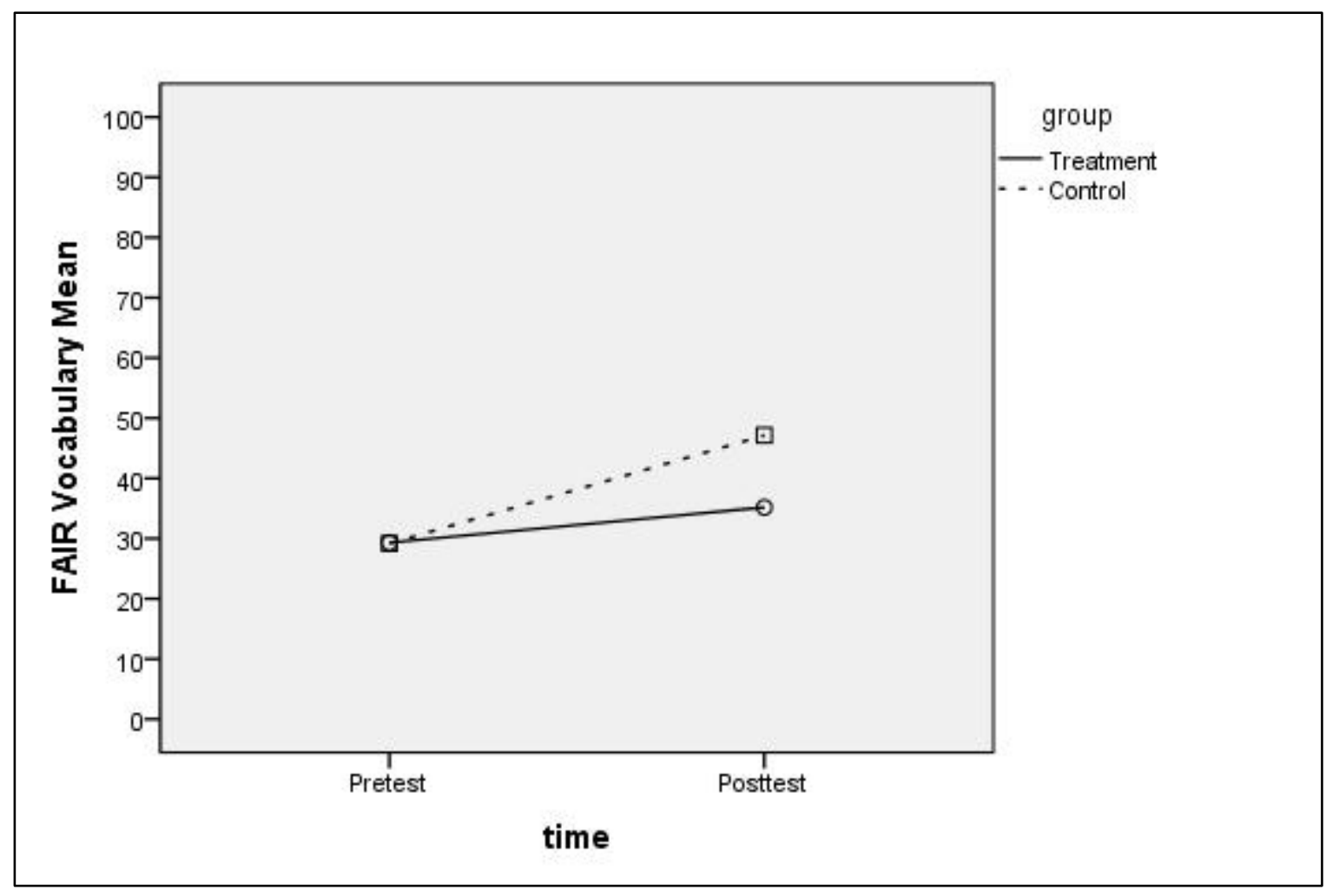

Figure 2. Pre and Adjusted Post FAIR Vocabulary Means by Group

There was not a significant difference in the adjusted Treasures Vocabulary means by group, $F(1,66)=0.92, p=.340, \eta^{2}=.01$. The treatment mean gain score $(\operatorname{adj} M$ $=8.26)$ was higher than that for the comparison group (adj $M=7.21)$, but did not reach statistical significance. Additional tests indicated that the Treasures Vocabulary means increased significantly for both groups from pre to posttest.

\section{Results for Research Question 2}

Research Question 2 asked if English learners (ELs) using a multimodal strategy approach (treatment) would show greater improvement in reading comprehension and vocabulary than ELs in the comparison group, as compared to the native speakers, and as measured by the FAIR Comprehension, the FAIR Vocabulary, and the Treasures 
Comprehension and Vocabulary tests. Two way ANCOVAs by group and EL status were carried out on the gain scores for each measure with the pretest as covariate. It was of interest to examine if interactions of group by EL status were statistically significant.

When evaluating the FAIR Comprehension gain scores, the ANCOVA did not indicate a significant interaction between group and EL status, $F(1,63)=0.97, p=.329$, $\eta^{2}=.02$. For the FAIR Vocabulary gain scores, there was not a significant interaction between group and EL status, $F(1.63)=0.30, p=.583, \eta^{2}=.01$. However, for the Treasures Vocabulary gain scores, the interaction of group and EL status nearly reached significance, $F(1,64)=2.84, p=.097, \eta^{2}=.042$. Exploring further, using Fisher's LSD post hoc test, the adjusted Treasures Vocabulary mean gain for the ELs in the treatment group $(M=9.09)$ was marginally significantly higher than for the ELs in the comparison group $(M=6.34), p=.068$. Thus, the ELs using the multimodal strategy approach (treatment) showed somewhat more improvement in vocabulary acquisition, as measured by the Treasures Vocabulary, than the ELs in the comparison group, shown in Table 6.

Table 6

Adjusted Mean Gains for Treasures Vocabulary by Group and English Learner Status

\begin{tabular}{llll}
\hline Status & Treatment & Comparison & $p$ value \\
\cline { 1 - 3 } & $\begin{array}{l}M \\
\text { EL }\end{array}$ & $\begin{array}{l}M \\
(\mathrm{SD})\end{array}$ & .068 \\
\cline { 2 - 3 } & 9.09 & 6.34 & \\
Non-EL & $(1.06)$ & $(1.03)$ & \\
& 7.13 & 8.17 & \\
& $(1.24)$ & $(1.13)$ & \\
\hline
\end{tabular}

Note. Adjusted mean gains are evaluated at pretest mean scores. 


\section{Additional Findings}

The Treasures Reading Series was used for story comprehension, using eight weekly story comprehension tests to track story comprehension progress and vocabulary comprehension scores over eight weeks. Repeated measures ANOVAs evaluated group differences for the eight Treasures Story Comprehension and Treasures Vocabulary scores.

The Treasures Story Comprehension showed no interaction by group across the eight stories, $F(1,469)=1.59, p=.211, \eta^{2}=.023$, as shown in Table 7. Although the results did not reach significance, the treatment group scored higher, on average, than the comparison group in six out of the eight weeks.

\section{Table 7}

Weekly Means of Treasures Story Comprehension Tests by Group

\begin{tabular}{|c|c|c|c|c|}
\hline \multirow[t]{3}{*}{ Week } & \multirow{2}{*}{\multicolumn{2}{|c|}{$\begin{array}{l}\text { Treatment } \\
(n=34)\end{array}$}} & \multirow{2}{*}{\multicolumn{2}{|c|}{$\begin{array}{l}\text { Comparison } \\
(n=35)\end{array}$}} \\
\hline & & & & \\
\hline & $M$ & $S E$ & $M$ & $S E$ \\
\hline 1 & 4.15 & .23 & 3.54 & .22 \\
\hline 2 & 4.38 & .21 & 4.17 & .21 \\
\hline 3 & 3.79 & .20 & 3.80 & .19 \\
\hline 4 & 4.56 & .19 & 4.06 & .19 \\
\hline 5 & 4.56 & .18 & 4.14 & .18 \\
\hline 6 & 4.12 & .19 & 3.69 & .19 \\
\hline 7 & 4.35 & .20 & 3.83 & .19 \\
\hline 8 & 4.15 & .18 & 4.20 & .18 \\
\hline
\end{tabular}


Table 8 shows that for all eight weeks, the treatment group scored higher on the Treasures Vocabulary than the comparison group. However, there was not a significant interaction by group across the eight stories, $F(1,469)=1.28, p=.265, \eta^{2}=.019$.

Table 8

Weekly Means of Treasures Vocabulary Comprehension by Group

\begin{tabular}{|c|c|c|c|c|}
\hline \multirow[t]{3}{*}{ Week } & \multirow{2}{*}{\multicolumn{2}{|c|}{$\begin{array}{l}\text { Treatment } \\
(n=34)\end{array}$}} & \multicolumn{2}{|l|}{ Comparison } \\
\hline & & & $(n=35)$ & \\
\hline & $M$ & SE & $M$ & $\mathrm{SE}$ \\
\hline 1 & 4.65 & .36 & 4.60 & .35 \\
\hline 2 & 5.18 & .30 & 4.69 & .30 \\
\hline 3 & 4.71 & .37 & 4.60 & .36 \\
\hline 4 & 4.68 & .40 & 3.40 & .39 \\
\hline 5 & 4.76 & .29 & 4.43 & .29 \\
\hline 6 & 5.03 & .27 & 4.60 & .27 \\
\hline 7 & 4.88 & .29 & 4.63 & .28 \\
\hline 8 & 5.18 & .28 & 4.77 & .28 \\
\hline
\end{tabular}

\section{Summary}

This chapter presented an analysis of the data related to the two hypotheses.

ANCOVAs were used to analyze the data. For Hypothesis 1, one way ANCOVAs by group were carried out on gain scores from pre to posttest for three measures, with the pretest as the covariate. For Hypothesis 2, two way ANCOVAs by group and EL status were carried out on the gain scores from pre to posttest for each measure, with the pretest as covariate. 
Hypothesis 1 was supported by the FAIR Comprehension scores. Students in the multimodal instructional framework approach classrooms (treatment group) scored significantly higher on the adjusted FAIR Comprehension posttest than the students in the traditional approach classrooms (comparison group). However, students in the treatment group did not improve on the FAIR Vocabulary as much as the comparison group did. There was not a significant difference in the adjusted Treasures Vocabulary means by group.

Hypothesis 2 was partially supported by the Treasures Vocabulary scores. English language learners using the multimodal instructional framework approach (treatment group) showed somewhat more improvement in vocabulary acquisition, as measured by the Treasures Vocabulary, than those in the comparison group, $p=.068$. No significant interactions of group by EL status were found for the other two measures. For the Treasures Story Comprehension and Vocabulary scores across the eight weeks, the treatment group scored higher, on average, than the comparison group in six out of the eight weeks for the story comprehension and eight out of the eight weeks for the vocabulary comprehension, although neither reached significance. This might indicate that more research and a longer time frame would be helpful in this area to attain better results over a longer period of time. The next chapter contains a discussion of those findings, as well as implications for further research. 


\section{CHAPTER V}

\section{DISCUSSION}

This chapter presents an overview of the study. A summary of the results by hypothesis is described in a discussion of the interpretations and meanings of the results. Following that is a discussion of the implications of this research on future practice. The chapter concludes with a summary of the major facets of the overall study.

\section{Overview of the Study}

This study was conducted to analyze the effectiveness of using a multimodal instructional framework of strategies on the reading comprehension skills of at-risk, diverse, first-grade students. The strategies used included a combination of visualization, story read-alouds, and onset and rime embedded within the reading lesson. Assessed skills were reading comprehension and vocabulary improvement leading to improved reading comprehension. The sample included 69 first-grade students at an inner city elementary school in large district in a southeastern state.

Four intact first-grade classrooms were assigned to either the treatment group or the comparison group. Two classes comprised the treatment group and two classes comprised the comparison group. The comparison group had vocabulary words introduced on Monday of each week, concluding with a test each Friday. The treatment group also had the vocabulary words introduced on Monday, and had pictures shown to them to illustrate each word. During the week, the treatment group drew their own pictures of each word, and wrote a sentence using that word on a large index card. Word games were played with the onset and rime words during reading each day. 
Pre and posttests were administered to both treatment and comparison groups. The FAIR (Florida Assessments for Instruction in Reading) Test was used as a pre and post for both comprehension and vocabulary. One added vocabulary pre and posttest was created using the 48 Treasures Reading Series vocabulary words that accompanied the Treasures stories during the study. In addition, a weekly test was given to both treatment and comparison groups on each of eight weekly stories and the accompanying vocabulary. Repeated measures ANOVAs were used to evaluate group differences for the eight week Treasures Story Comprehension and Treasures Vocabulary Comprehension scores. Each group took either a pretest on the first 24 words (List A), or words 25 through 48 (List B). The posttest was the other set of words. One treatment class took a pretest on Treasures Vocabulary Test List A. The second treatment class took the pretest on Treasures Vocabulary Test List B. The comparison group did the same, with one class taking Vocabulary Test List A as the pretest, and the other class taking Vocabulary Test List B as the pretest. For the posttest, each group took the other test. If they took List A as a pretest, then they took List B as a posttest.

\section{Summary of the Results}

The first hypothesis was used to test the effectiveness of using a multimodal instructional framework of strategies on the comprehension and vocabulary skills of atrisk, diverse, first-grade students at an inner city school. Hypothesis 1 was supported by the FAIR Comprehension data, indicating that students in the multimodal instructional framework approach classrooms scored significantly higher on the adjusted FAIR Comprehension posttest than the students in the traditional approach classrooms. However, the treatment group's FAIR Comprehension means did not significantly 
increase from pre to post, but the comparison group's means decreased significantly from pre to post. The analysis of the adjusted FAIR Vocabulary mean gain scores indicated that the treatment group improved significantly on the FAIR Vocabulary as did the comparison group, but the comparison group improved significantly more. The vocabulary words from the FAIR 1 and 3 were the same words, however, the words were not the onset-and-rime words that were the focus of the study. The Florida Assessments for Instruction in Reading words, which were mostly tier 2 type words, were words that may have been introduced to both groups during instruction in other areas. Also note that the FAIR Vocabulary posttest was administered 8 weeks after intervention. The treatment mean gain score for the Treasures Vocabulary was higher than that of the comparison group, but did not reach statistical significance. Additional tests indicated that the Treasures Vocabulary means increased significantly for both groups.

The second hypothesis was used to test the effectiveness of using a multimodal strategy framework to see if English language learners (ELs) in the treatment group made larger gains in reading comprehension and vocabulary than ELs in the comparison group. Neither the FAIR Comprehension gain scores, nor the FAIR Vocabulary gain scores indicated a significant interaction between group and EL status. However, for the Treasures Vocabulary gain scores, the interaction of group and EL status nearly reached significance. The adjusted mean gain for the ELs in the treatment group was somewhat higher than for the ELs in the comparison group.

Additional findings, using repeated measures ANOVAs for eight weekly Treasures Comprehension story tests and Treasures Vocabulary tests, showed no difference by group across the eight stories. Although the results did not reach 
significance, the treatment group scored higher on the comprehension, on average, than the comparison group in six out of eight weeks, and higher on the vocabulary in all eight weeks. This might be attributed to the treatment strategies used.

\section{Discussion}

The purpose of this study was to determine the effectiveness of using a multimodal framework of strategies to increase diverse first-grade students' vocabulary acquisition, leading to improved vocabulary comprehension. The study also sought to determine the effectiveness of the multimodal framework of strategies on English learners. Several strategies were used together in an attempt to create the desired effect.

FAIR was chosen as a pre and posttest because it had a comprehension section as well as a vocabulary section, and all first-grade students were required to take that assessment. That generated pre and posttest scores for the comprehension and vocabulary that could be used for comparison purposes. The decision to do the study for eight weeks was a direct result of the length of a school year quarter. The traditional approach had inconclusive results as did the treatment approach. Although the treatment group on the FAIR Comprehension test scores did not significantly increase from pre to posttest, the comparison group means decreased significantly from pre to posttest scores, indicating that possibly the multimodal strategy did have an effect. On the adjusted FAIR Vocabulary test mean gain scores, the comparison group improved more than the treatment group. If the multimodal strategies treatment were applied to the vocabulary words from FAIR, the results might have been better for the treatment group, but those words were not included in the treatment. The treatment mean gain for the Treasures vocabulary was higher than that of the comparison group, but did not reach statistical 
significance, although additional tests indicated that the Treasures Vocabulary means increased significantly from pre to post for both groups. Perhaps more testing would indicate more concise results for the multimodal framework of strategies.

While interpreting the results of this study, several factors need to be considered. The study lasted only 8 weeks. A longer time period might have produced more concrete results. The FAIR (Florida Assessments for Instruction in Reading) Comprehension section can become harder from Assessment 1 to Assessment 2, depending on how well a student does on reading a word list. Student performance on the word list determines the passage he will be given to start FAIR Assessment 2. Although the words used on the FAIR were not studied by the students, treatment might have had a bearing on the outcome. The FAIR Vocabulary Assessment is the same from Assessment 1 to Assessment 3. The vocabulary assessment is not given in Assessment 2. The FAIR Vocabulary words were not onset-and-rime words and were not present in the Treasures stories. Again, the FAIR Vocabulary words were not given the multimodal treatment. If the treatment had been given to the FAIR Vocabulary words, there might have been a positive effect on the outcome.

The results of the study were multifaceted, like the framework of the strategies used in the study. The multimodal instructional framework of strategies included having students use visualization, student-generated pictures of onset-and-rime-patterned vocabulary, and story read-alouds with discussion, to enable diverse first-grade students to increase their vocabularies and comprehension. There is data to support the idea that the strategies used benefited the treatment group and the EL students in the treatment group. Although the FAIR Vocabulary comparison group showed more increase than the 
treatment group, both groups increased, which is encouraging. The Treasures Vocabulary treatment group showed more gain than the comparison group, and though not significant, still shows promise. Treasures Comprehension scores for the treatment group were not significant, but did show the treatment group scoring higher than the comparison group on six out of eight weekly tests. FAIR Comprehension scores were significant in that although the treatment group did not score higher on the posttest, the comparison group scored lower on the posttest. It is possible that the treatment group remained at the same level due to the multimodal strategy treatment received, while the comparison group scored lower.

Limited vocabulary is a problem in diverse, low socio-economic areas. Students often do not have much parental involvement due to several factors. Often the parents have more than one job and do not have time for much interaction with their children. Lack of income can keep parents form taking their children out to events that might stimulate their minds and increase their world knowledge, especially their vocabulary. Talk time between parent and child is not nearly enough for the child to build a vocabulary store, and there is often limited access to books for the students to read. Other factors include the number of parents in the household, and level of parent education. All of these things are factors that might work against vocabulary growth.

Students in the treatment group seemed to enjoy the multimodal experience, and were always willing to participate. Research has shown that when students enjoy an activity, they tend to learn in a timely manner. Involving students in a variety of ways helps ensure that learning will take place. If students do not increase their vocabulary stores on a growing basis, the educational implications are bleak. 
Because there is a great deal of research that tells us that vocabulary level is a measure of comprehension, it is imperative to use the best strategies and methods available in order to support the diverse first-grade students.

\section{Implications}

As Heibert (2009) pointed out, current basals are designed for the majority students. These basals do not address the needs of our growing, diverse population. More relevant cultural and linguistic additions to basals would be a positive move forward for the diverse students. More scaffolding of language learners is needed in our schools. Teachers in diverse schools should have cultural background knowledge for the benefit of their students. Including the 2,000 most important words for English learners on elementary vocabulary lists would also be of value. Schools need to be more culturally aware of their diverse students and their particular needs.

This study has shown some evidence that supports using a multimodal instructional framework of strategies to improve the comprehension and vocabulary skills of at-risk, diverse first-grade students. While the study showed promise for the use of the multimodal instructional framework of strategies, future research on strategy combinations should be pursued. Based on these findings, it is important to continue to explore combinations of strategies that may facilitate learning for at-risk, diverse students, ELs, and all students in general. It is a fact that not all students learn in the same way. Therefore, a multimodal instructional framework of strategies could be the key to the future acquisition of vocabulary, leading to improved comprehension.

As stated earlier, basals do not effectively address the needs of the EL students (Heibert, 2009). Due to the fact that the multimodal framework of strategies had limited 
success despite good intentions, a bilingual approach might be one way of addressing the issue of vocabulary acquisition and comprehension improvement for the ELs. Benefits might be achieved using a bilingual teaching method, which would require that the teachers be bilingual.

Continued research is necessary in order to address the vocabulary differences in students from low socioeconomic backgrounds and students from higher socioeconomic backgrounds (Hart \& Risley, 1995; Sharif, Ozuah, Dinkevich, and Mulvihill, 2003). An effort should be made to erase the differences early in the schooling of these students. Future research is needed to ensure that early elementary students get adequate instruction in vocabulary acquisition, which research has shown may lead to improved comprehension. 


\section{REFERENCES}

Adams, M. J. (1990). Beginning to read. Cambridge, MA: MIT Press.

Adams, M. J. (2011). Advancing our students language and literacy. American Educator, 3-11.

Allington, R. (2002). Big brother and the national reading panel. Portsmouth, NH: Heinemann.

Anderson, R. C., \& Freebody, P. (1981). Vocabulary knowledge. In J. T. Guthrie (Ed.), Comprehension and teaching: Research reviews (pp. 77-117). Newark, DE: International Reading Association.

Baumann, J. F. (2009). Vocabulary and reading comprehension: the nexus of meaning. In S. E. Israel, \& G. G. Duffy (Eds.), Handbook of research on reading comprehension (pp. 323-346). New York, NY: Routledge.

Beck, I. L., \& McKeown, M. G. (2001). Text talk: Capturing the benefits of read aloud experiences for young children. The Reading Teacher, 55(1), 10-20.

Beck, I. L., \& McKeown, M. G. (2007). Increasing young low-income children's oral vocabulary repertoires through rich and focused instruction. Elementary School Journal, 107(3), 251-269.

Beck, I. L., McKeown, M. G., \& Kucan, L. (2002). Bringing words to life: Robust vocabulary instruction. New York, NY: The Guilford Press.

Beck, I. L., Perfetti, C. A., \& McKeown, M. G. (1982). Effects of long term vocabulary instruction on lexical access and reading comprehension. Journal of Educational Psychology, 74(4), 506-521.

Becker, W. C. (1977). Teaching reading and language to the disadvantaged-What we have learned from field research. Harvard Educational Review, 47(4), 518-543.

Berne, J. I., \& Blachowicz, C. L. (2009). What reading teachers say about vocabulary instruction: Voices from the classroom. The Reading Teacher, 62(4), 314-323.

Biemiller, A. (2004). Teaching vocabulary in the primary grades: Vocabulary instruction needed. In J. F. Bauman, \& E. J. Kame’enui (Eds.), Vocabulary instruction: Research to practice (pp. 28-40). New York, NY: The Guilford Press.

Biemiller, A., \& Boote, C. (2006). An effective method for building meaning vocabulary in primary grades. Journal of Educational Psychology, 98(1), 44-62. 
Biemiller, A., \& Slonim, N. (2001). Estimating root word vocabulary growth in normative and advantaged populations: Evidence for a common sequence of vocabulary acquisition. Journal of Educational Psychology, 93(3), 498-512.

Blachowicz, C. L., \& Fisher, P. (2000). Vocabulary instruction. In M. L. Kamil, P. B. Rosenthal, P. D. Pearson, \& R. Barr (Eds.), Handbook of Reading Research (3rd ed., pp. 503-524). Mahwah, NJ: Lawrence Erlbaum Associates.

Blachowicz, C. L., \& Fisher, P. (2004). Vocabulary Lessons. Educational Leadership, 61(6), 66-69.

Blachowicz, C. L., Fisher, P. J., Ogle, D., \& Watts-Taffe, S. (2006). Vocabulary: questions from the classroom. Reading Research Quarterly, 41, 524-539.

Brabham, E. G., \& Lynch-Brown, C. (2002). Effects of teachers' reading-aloud styles on vocabulary acquisition and comprehension of students in early elementary grades. Journal of Educational Psychology, 94(3), 465-473.

Brabham, E. G., \& Villaume, S. K. (2002). Vocabulary instruction: Concerns and visions. The Reading Teacher, 56(3), 264-268.

Bryant, D. P., Goodwin, M., Bryant, B. R., \& Higgins, K. (2003). Vocabulary instruction for students with learning disabilities: A review of the research. Learning Disability Quarterly, 26(2), 117-128.

Buros Center for Testing. (2010). Review of Florida Assessments for Instruction in Reading, 38-55.

Bustle, L. S. (2004). The role of visual representation in the assessment of learning. Journal of Adolescent \& Adult Literacy, 4(5), 415-423.

Canning-Wilson, C. (2001). Visuals \& language learning: Is there a connection [article]. Retrieved from eltnewsletter: http://www.eltnewsletter.com/back/Feb2001/art482001.htm

Coyne, M. D., Simmons, D. C., Kame'enui, E. J., \& Stoolmiller, M. (2004). Teaching vocabulary during shared storybook readings: An examination of differential effects. Exceptionality, 12(3), 145-162.

Cunningham, A. E., \& Stanovich, K. E. (1997). Early reading acquisition and its relation to reading experience and ability 10 years later. Developmental Psychology, 33(6), 934-945. 
Cunningham, J. (2001). Report of the National Reading Panel: Teaching children to read: An evidence-based assessment of the scientific research literature on reading and its implications for reading instruction. Reading Research Quarterly, 36(3), 326-335.

Cunningham, P. M., \& Cunningham, J. W. (2002). What we know about how to teach phonics. In A. E. Farstrup, \& S. J. Samuels (Eds.), What research has to say about reading instruction (3rd ed., pp. 87-109). Newark, DE: International Reading Association.

Davis, F.B. (1942). Two new measures of reading ability. Journal of Educational Psychology, 33, 365-372.

Florida Center for Reading Research. (2008). Florida Assessments for Instruction in Reading, Florida Department of Education.

Graves, M. F. (2006). The vocabulary book: Learning and instruction. New York, NY: Teachers College Press.

Harris, T. L., \& Hodges, R. E. (Eds.). (2005). The literacy dictionary: The vocabulary of reading and writing. Newark: DE: International Reading Association.

Hart, B., \& Risley, T. R. (1995). Meaningful differences in the everyday experiences of young American children. Baltimore, MD: Paul H. Brookes.

Hart, B., \& Risley, T. R. (2003). The early catastrophe: The 30 million word gap by age 3. American Educator, 27(1), 4-9.

Hart, T. M., Berninger, V. M., \& Abbott, R. D. (1997). Comparison of teaching single or multiple orthographic-phonological connections for word recognition and spelling: Implications for instructional consultation. The School Psychology Review, 26(2), 279-297.

Heibert, E. H. (2009). The (mis)match between texts and students who depend on schools to become literate. In E. H. Heibert \& M. Sailors (Eds.) Finding the right texts: What works for beginning and struggling readers (pp. 1-20). New York: Guilford Press.

Heibert, E. H., \& Martin, L. A., (2009). Repetition of words: The forgotten variable in texts for beginning and struggling readers. In E. H. Heibert \& M. Sailors (Eds.), Finding the right texts for beginning and struggling readers: Research-based solutions (pp. 47-69). NY: Guilford Press. 
Hollis, E. R., \& Guzman, M. T. (2005). Research for preparing teachers for diverse populations. In M. Cochran-Smith, \& K. M. Zeicher (Eds.), Studying teacher education: The report of the AERA Panel on research and teacher education (Ch. 8), Mahwah, NJ: Lawrence Erlbaum Associates.

Jalongo, M. (2007). Early Childhood Language Arts (4th ed.). New York, NY: Pearson, Allyn, and Bacon.

Juel, C., Biancarosa, G., Coker, D., \& Deffes, R. (2003). Walking with Rosie: A cautionary tale of early reading instruction. Educational Leadership, 13-18.

Juel, C., \& Deffes, R. (2004). Making Words Stick. Educational Leadership, 6(6), 30-34.

Juel, C., \& Roper/Schneider, D. (1985). The influence of basal readers on first grade reading. Reading Research Quarterly, 20(2), 134-152.

Lapp, D., Flood, J., Moore, K., \& Nichols, M. (2005). Teaching literacy in first grade. New York, NY: The Guilford Press.

Manning, M. (2002). Visualizing while reading. Teaching PreK-8, 32(8), 88-90.

Marzano, R., Pickering, D., \&Pollock, J. (2001). Classroom instruction that works: Research-based strategies for increasing student achievement. Alexandria, VA: Association for Supervision \& Curriculum Development.

Maynard, K. L., Pullen, P. C., \& Coyne, M. D. (2010). Teaching vocabulary to first grade students through repeated shared reading: A comparison of rich and basic instruction to incidental exposure. Literacy Research and Instruction, 49(3), 209242.

McKeown, M. G., \& Beck, I. L. (1988). Learning vocabulary: Different ways for different goals. Remedial and Special Education, 9(1), 42-52.

Moats, L. (2000). Whole language lives on: The illustration of "balanced" reading instruction. Thomas B. Fordham Foundation: Outside the Box.

Nagy, W. E., \& Scott, J. A. (2000). Vocabulary processes. In M. L. Kamil, P. B. Mosenthal, P. D. Pearson, \& R. Barr (Eds.), Handbook of reading research (pp. 269-284). Mahwah, NJ: Lawrence Erlbaum Associates.

Nation, P. (2000). Learning vocabulary in lexical sets: Dangers and guidelines. TESOL Journal, 9(2), 6-10. 
National Reading Panel Report. (2000). In Teaching children to read: An evidence-based assessment of the scientific research literature on reading and its implications for reading instruction. Washington, DC: National Institute of Child Health and Human Development.

Newman, I., Newman, C., Brown, R., \& McNeely, S. (2006). Conceptual statistics for beginners (3rd ed.). Lanham, MD: University Press of America.

Opitz, M. F., \& Rasinski, T. V. (1998). Good-bye round robin: Twenty-five effective oral reading strategies. Portsmouth, $\mathrm{NH}$ : Heinemann.

Pearson, P. D., Hiebert, E., \& Kamil, M. (2007). Vocabulary assessment: What we know and what we need to learn. Reading Research Quarterly, 42(2), 282-296.

Qi, C. H., Kaiser, A. P., Milan, S., \& Hancock, T. (2006). Language performance of lowincome African American and European American preschool children on the PPVT-III. Language, Speech, and Hearing Services in Schools, 37, 5-16.

Restrepo, M. A., Schwanenflugel, P. J., Blake, J., Neuharth-Pritchett, S., Cramer, S. E., \& Ruston, H. P. (2006). Performance on the PPVT-III and the EVT: Applicability of the measures with African American and European American preschool children. Language, Speech, and Hearing Services in Schools, 37, 17-27.

Rupley, W. H., Logan, J. W., \& Nichols, W. D. (1999). Vocabulary instruction for the struggling reader. Reading and Writing Quarterly, 52(4), 238-247.

Sharif, I., Ozuah, P. O., Dinkevich, E. I., \& Mulvihill, M. (2003). Impact of a brief literacy intervention on urban preschoolers. Early Childhood Education Journal, 30(3), 177-180.

Stahl, S. A., \& Nagy, W. E. (2006). Teaching word meanings. Mahwah, NJ: Lawrence Erlbaum Associates.

Stahl, S. A., \& Stahl, K. A. (2004). Word wizards all! In J. F. Baumann, \& E. J. Kame'enui (Eds.), Vocabulary instruction: Research to practice (pp. 59-78). New York, NY: Guildford Press.

Texas Reading Initiave (2002). Promoting vocabulary development: Components of effective vocabulary instruction. Manuscript in preparation.

Uberti, H. Z., Scruggs, T. E., \& Mastropieri, M. A. (2003). Keywords make the difference: Mnemonics instruction in inclusive classrooms. Exceptional Children, 35(3), 56-61. 
Uccelli, P., \& Paez, M. M. (2007). Narrartive and vocabulary development of bilingual children from kindergarten to first grade: Developmental changes and associations among English and Spanish skills. Language, Speech, and Hearing Services in Schools, 38(3), 225-236.

U. S. Census Bureau (2010). 2010 Census interactive population search. Retrieved from http://2010.census.gov/2010census/popmap/ipmtext.php?fl=12

Vaughn-Shavou, F. (1990). Using story grammar and language experience for improving recall and comprehension in the teaching of ESL to Spanish-dominated first graders (Unpublished doctoral dissertation). Hofstra University, Hempstead, NY.

Vesley, P., \& Gryder, N. (2007). Teaching visual imagery for vocabulary learning. Academic Exchange Quarterly, 11.2, 51-56.

Weber, R., \& Longhi-Chirlin, T. (2001). Beginning in English: The growth of linguistic and literate abilities in Spanish-speaking first graders. Reading Research and Instruction, 4l(1), 19-48.

Webster's Universal College Dictionary. (1997). New York, NY: Gramercy Books.

White, T. G. (2005). Effects of systematic and strategic analogy-based phonics on grade 2 students' word reading and reading comprehension. Reading Research Quarterly, 40(2), 234-255.

Wilkinson, I. A., \& Son, E. H. (2011). A dialogic turn in research on learning to comprehend. In M. L. Kamil, P. D. Pearson, E. B. Moje, \& P. P. Afflerbach (Eds.), Handbook of Reading Research (4th ed., pp. 359-387). New York, NY: Routledge.

Williams, J., \& Dwyer, F. (2004). The relative effectiveness of varied visual testing formats in retrieving information related to different educational objectives. International Journal of Instructional Media, 31(2), 257-266. 


\section{APPENDIX A}

Pattern Words, Read-Aloud Stories and Leveled Books

Week 1

Story: Pam and Sam by Nancy Tafuri

Leveled Readers:

Below Level: Cat Can Jump by Yoki Hira

On Level: Can You? by Paul Dan, illustrated by Jill Newton

English language learner: I Can! By Paul Dan, illustrated by Jill Newton

Above Level: Look at Chameleon! By Cynthia Rothman, illustrated by Jason Wolff

Onset-and Rime Words

Hat

Mat

Cat

Ran

Man

Can

Week 2

Story: I Can, Can You? by Cathy Roper, illustrated by Lorinda Bryan Cauley

Leveled Readers:

Below Level: Move! Push! Pull! by Liane B. Onish

On Level: Move! Push! Pull! by Liane B. Onish

Above Level: Move! Push! Pull! by Liane B. Onish

English language learners: Move! Push! Pull! by Liane B. Onish

Onset-and-Rime Words:

Dad

$\mathrm{Sad}$

Sack

Back

Nap

Tap 


\section{Week 3}

Story: How You Grew, nonfiction with no author

Leveled Readers:

Below Level: A Frog Grows and Changes by Christy Steele

On Level: A Frog Grows and Changes by Christy Steele

Above Level: A Frog Grows and Changes by Christy Steele

English language learner: A Frog Grows and Changes by Christy Steele

Onset-and-Rime Words:

Win

Pin

Kiss

Miss

Sit

Hit

Week 4

Story: Pet Tricks by Ed Reyes

Leveled Readers:

Below Level: Good Cat by Christina Reyes

On Level: My Pet Hamster by David Michaels, illustrated by Karen Stormer Brooks

Above Level: Rosa's New Puppy by Julia Diago, illustrated by John Wallace

English language learner: A Puppy for Rosa by Julia Diago, illustrated by John Wallace

Onset-and-Rime Words:

Crab

Grab

Trip

Crib

Trap

Grass 


\section{Week 5}

Story: Soccer by Patrick Lee

Leveled Readers:

Below Level: All Kinds of Teams by Bonnie Ferraro

On Level: All Kinds of Teams by Bonnie Ferraro

Above Level: All Kinds of Teams by Bonnie Ferraro

English language learner: All Kinds of Teams by Bonnie Ferraro

Onset-and-Rime Words:

Land

Sand

Sink

West

Fast

Sent

Week 6

Story: Animal Moms and Dads by Jose Ramos

Leveled Books:

Below Level: What Are Living Things? by Christy Steele

On Level: What Are Living Things? by Christy Steele

Above Level: What Are Living Things? by Christy Steele

English language learner: Living Things by Christy Steele

Onset-and-Rime Words:

Hop

Top

$\log$

Hog

Hot

Lot 


\section{Week 7}

Story: Little Red Hen retold by Cynthia Rothman

Leveled Books:

Below Level: Trees Help by Angela Rios

On Level: Trees Help by Angela Rios

Above Level: Trees Help by Angela Rios

English language learner: Trees by Angela Rios

Onset-and-Rime Words:

Leg

Beg

Men

Hen

Get

Let

Week 8

Story: A Prairie Dog Home nonfiction with no author

Leveled Books:

Below Level: Polar Bears by Liane B. Onish

On Level: Polar Bears by Liane B. Onish

Above Level: Polar Bears by Liane B. Onish

English language learner: Polar Bears by Liane B. Onish

Onset-and-Rime Words:

Fish

Ship

Shop

Thin

With

Thank 


\section{APENDIX B}

Weekly Story Comprehension Tests

Week 1 Comprehension Test

Story: Pam and Sam by Nancy Tafuri

Circle the letter next to the best answer.

1. Pam and Sam like to
A. Eat
B. Play
C. Nap

2. Pam and Sam are
A. Rabbits
B. Brother and sister
C. Friends

3. Pam and Sam can together.
A. Jump
B. Run
C. Fly

4. When Pam ran up, Sam ran
A. Up
B. Down
C. Not

5. Pam can jump. But Sam can
A. Swim
B. Skip
C. Fly 


\section{Week 2 Comprehension Test}

Story: I Can, Can You? by Cathy Roper, illustrated by Lorinda Bryan Cauley

Circle the letter next to the best answer.

1. In the story, the boy can do what the girl
A. Cannot do
B. Does not like to do
C. Can do

2. The girl hops, and then the boy , too.
A. Hops
B. Runs
C. Naps

3. The girl and the boy can jump a mat.
A. Like
B. Over
C. With

4. When the girl can tap, tap, tap, the boy can
A. Hop, hop, hop
B. Jump, jump, jump
C. Nap, nap, nap

5. In the end, can the girl do what the boy can do?
A. Yes, she can
B. No, she cannot
C. No, he does not let her 


\section{Week 3 Comprehension Test}

Story: How You Grew nonfiction with no author

Circle the letter next to the best answer.

1. How does the story start?
A. You are a baby.
B. You are five.
C. You are old.

2. As a baby, you learned to first.
A. Ride
B. Talk
C. Run

3. If you could eat at the table, you must know how to
A. Sit
B. Run
C. Sing

4. Children could learn to fast.
A. Play with
B. Run and ride
C. Fly

5. What happens when you get older?
A. You learn new things.
B. You get smaller.
C. You eat less. 


\section{Week 4 Comprehension Test}

Story: Pet Tricks by Ed Reyes

Circle the letter next to the best answer.

1. The story takes place at a
A. Zoo
B. Pet show
C. Farm

2. The children are there to watch the pets
A. Get new homes
B. Play with each other
C. Do tricks

3. Ham the hamster can run the track.
A. On
B. For
C. Jump

4. Which pet can jump over a bat?
A. Frizz the dog
B. Ham the hamster
C. Kit the cat

5. What good trick can Kit the cat do?
A. Kit can grab the rope.
B. Kit can jump over a bat.
C. Kit can kiss. 


\section{Week 5 Comprehension Test}

Story: Soccer by Patrick Lee

Circle the letter next to the best answer.

1. Frank will__t the children play soccer.
A. Now
B. Use
C. Help

2. You use to move the ball in soccer.
A. A bat
B. Your feet
C. The net

3. The children very fast to get the ball.
A. Run
B. Jump
C. Talk

4. One player can grab the ball with
A. A net
B. Her hands
C. Her head

5. What is this story about?
A. A funny story
B. How to play in the park
C. How to play soccer 


\section{Week 6 Comprehension Test}

Story: Animal Moms and Dads by Jose Ramos

Circle the letter next to the best answer.

1. There is_baby in the tree.
A. Two
B. One
C. They

2. Some animal dads their babies.
A. Pick bugs off
B. Run and jump
C. Fly

3. Animal moms and dads bring to their babies.
A. Back
B. Hop
C. Food

4. How does one animal mom make her baby soft?
A. She licks
B. She hops
C. She plays

5. What did the mom and dad birds do?
A. Build a nest
B. Hop, hop, hop
C. Pick off bugs 


\section{Week 7 Comprehension Test}

Story: Little Red Hen retold by Cynthia Rothman

Circle the letter next to the best answer.

1. Little Red Hen has a bit of
A. Corn
B. Wheat
C. Hay

2. Hen gets water from the
A. Well
B. Lake
C. Barn

3. Who helps Hen "mix and mix?"
A. Pig
B. Cat
C. No one

4. Cat and Pig want to help Hen the bread.
A. Some
B. Plant
C. Eat

5. Hen does not the bread.
A. Eat
B. Share
C. Plant 


\section{Week 8 Comprehension Test}

Story: A Prairie Dog Home nonfiction with no author

Circle the letter next to the best answer.

1. Prairie dogs live
A. In trees
B. In the water
C. Under the land

2. Prairie dogs live with other prairie dogs.
A. Into
B. Many
C. Out

3. Prairie dogs keep food in the
A. Food room
B. Nursery
C. Sleeping room

4. How do prairie dogs dig?
A. With their legs
B. With big claws
C. With their tails

5. This story is about prairie dogs
A. Playing in the grass
B. Making a home
C. Digging long paths 


\section{APPENDIX C}

Decodable Readers

Decodable Reader for Unit 1

All About Us

Stories include:

Week 1: A Cap for Pam by Kathryn Lewis, illustrated by Chi Chung

Week 2: I Can, I Can! By Carol Lindeen

Week 3: Jim Had a Big Hit! By Liz Rivera, illustrated by Kathryn Mitter

Week 4: Grab a Crab by Mindy Menschell

Week 5: Kids Can Do It Fast! by Ming Chin Lee

Decodable Reader for Unit 2

Outside My Door

Week 6: Fox on a Rock by Marsha Gilmore, illustrated by Aleksey Ivanov

Week 7: Hen's Eggs by Wiley Blevins, illustrated by Anthony Lewis

Week 8: This Fish, That Fish by Maryann Dobeck 


\section{APPENDIX D}

Vocabulary Tests for Treasures Words

Vocabulary Test for Pam and Sam

Word choices for blanks:

man, ran, cat, can, hat, mat

1. Can you see the furry

2. The cat is resting on the

3. The man put the on his head.

4. That is my father.

5. Open the of soup for lunch.

6. I in the race. 
Vocabulary Test for I Can, Can You?

Word choices for blanks:

dad, sad, nap, tap, sack, back

1. She can ___ her pencil and make a sound.

2. She was _ when her dog ran away.

3. Babies like to sleep, so they take a

every afternoon.

4. His___ works in an office.

5. She will help her mom bring in the of groceries.

6. I got a sun-burn on my 
Vocabulary Test for How You Grew

Word choices for blanks:

pin, win, hit, sit, miss, kiss

1. Here is a chair for you to on.

2. Use the baseball bat to the ball.

3. I will my medal on my shirt.

4. John will probably ____ the spelling bee.

5. My mom gives me a___ goodnight.

6. When you move away, I will you. 
Vocabulary Test for Pet Tricks

Word choices for blanks:

crib, crab, grab, trap, trip, grass

1. The baby will sleep in his

2. Dad needs to mow the

3. A___ is an animal that you see at the beach.

4. Let's go on a to Disney World!

5. Do not my arm because it hurts.

6. We caught an animal in the 
Vocabulary Test for Soccer

Word choices for blanks:

land, sand, fast, west, sink, sent

1. Put your dirty dishes in the

2. We will plant our garden on this plot of

3. Grandma_me a letter in the mail.

4. At the beach we will make a___ castle.

5. An airplane travels very

6.__ is a direction on a map. 
Vocabulary Test for Animal Moms and Dads

Word choices for the blanks:

hop, top, log, hog, hot, lot

1. Frogs can

2. We will park our car in the parking

3. Put the on the bottle.

4. The weather is so___ that ice cubes melt in my drink.

5. Dad put a on the fire to make it burn better.

6. My pet likes to roll in the mud. 
Vocabulary Test for Little Red Hen

Word choices for blanks:

leg, get, beg, let, men, hen

1. My pet___ lays eggs.

2. I kick a soccer ball with my

3. There are five ___ playing basketball.

4. I will go ___ my ball.

5. I will ___ the men to let me play ball with them.

6. Maybe they will___ me play if I ask nicely. 
Vocabulary Test for A Prairie Dog Home

Word choices for blanks:

fish, ship, thin, with, shop, thank

1. Please remember to

Grandma for the

birthday present.

2. If you do not eat much you will be

3. Let's take a cruise on a big

4. Mom needs to go to the grocery and

for food.

5. Can I come you?

6. Many swim in the ocean. 


\section{APPENDIX E}

Treasures Vocabulary Pre and Posttest List A and List B

List A

1. hat

2. mat

3. cat

4. dad

5. sad

6. sack

7. win

8. pin

9. kiss

10. crab

11. grab

12. crib

13. land

14. sand

15. sink

16. hop

17. top

18. hot

19. fish

20. ship

21. shop

22. leg

23. beg

24. let
List B

25. ran

26. man

27. can

28. nap

29. tap

30. back

31. sit

32. hit

33. miss

34. trip

35. trap

36. grass

37. west

38. fast

39. sent

40. $\log$

41. hog

42. lot

43. thin

44. with

45. thank

46. men

47. hen

48. get 


\section{APPENDIX F}

Schedules for Treatment and Comprehension Groups

\begin{tabular}{|c|c|c|}
\hline Time & Treatment Group & Comparison Group \\
\hline 2 weeks & $\begin{array}{l}\text { Pretest } \\
\text { FAIR Comprehension } \\
\text { FAIR Vocabulary }\end{array}$ & $\begin{array}{l}\text { Pretest } \\
\text { FAIR Comprehension } \\
\text { FAIR Vocabulary }\end{array}$ \\
\hline \multirow[t]{5}{*}{ Story 1} & $\begin{array}{l}\text { Monday } \\
\text { 1. } 2 \text { minutes } \\
\text { Teacher introduces } \\
\text { words. There are six } \\
\text { onset and onset-and rime } \\
\text { words, two review words } \\
\text { from the week before, } \\
\text { and two high frequency } \\
\text { words. This study will } \\
\text { look only at the six onset, } \\
\text { and onset-and-rime } \\
\text { words. }\end{array}$ & $\begin{array}{l}\text { Monday } \\
\begin{array}{l}\text { 1. } 2 \text { minutes } \\
\text { Teacher introduces } \\
\text { words. There are six } \\
\text { onset and onset-and } \\
\text { rime words, two review } \\
\text { words from the week } \\
\text { before, and two high } \\
\text { frequency words. This } \\
\text { study will look only at } \\
\text { the six onset, and onset- } \\
\text { and-rime words. }\end{array}\end{array}$ \\
\hline & $\begin{array}{l}\text { 2. } 2 \text { minutes } \\
\text { Teacher acts out words or } \\
\text { shows objects or pictures } \\
\text { of each word. }\end{array}$ & $\begin{array}{l}\text { 2. } 2 \text { minutes } \\
\text { Teacher discusses } \\
\text { Words' meanings }\end{array}$ \\
\hline & $\begin{array}{l}\text { 3. } 3 \text { minutes } \\
\text { Teacher discusses words' } \\
\text { meanings. }\end{array}$ & $\begin{array}{l}\text { 3. } 4 \text { minutes } \\
\text { Teacher models use of } \\
\text { words in sentences. }\end{array}$ \\
\hline & $\begin{array}{l}\text { 4. } 4 \text { minutes } \\
\text { Teacher models use of } \\
\text { words in sentences and } \\
\text { asks students to use } \\
\text { words in sentences. }\end{array}$ & $\begin{array}{l}\text { 4. } 8 \text { minutes } \\
\text { Teacher has students } \\
\text { copy words into their } \\
\text { school agendas. }\end{array}$ \\
\hline & $\begin{array}{l}\text { 5. } 4 \text { minutes } \\
\text { Teacher writes one } \\
\text { sentence per word on the } \\
\text { board so that students can } \\
\text { copy the sentences. If }\end{array}$ & $\begin{array}{l}\text { 5. } 4 \text { minutes } \\
\text { Teacher asks students to } \\
\text { volunteer to use words } \\
\text { in sentences and say } \\
\text { their sentences aloud to }\end{array}$ \\
\hline
\end{tabular}




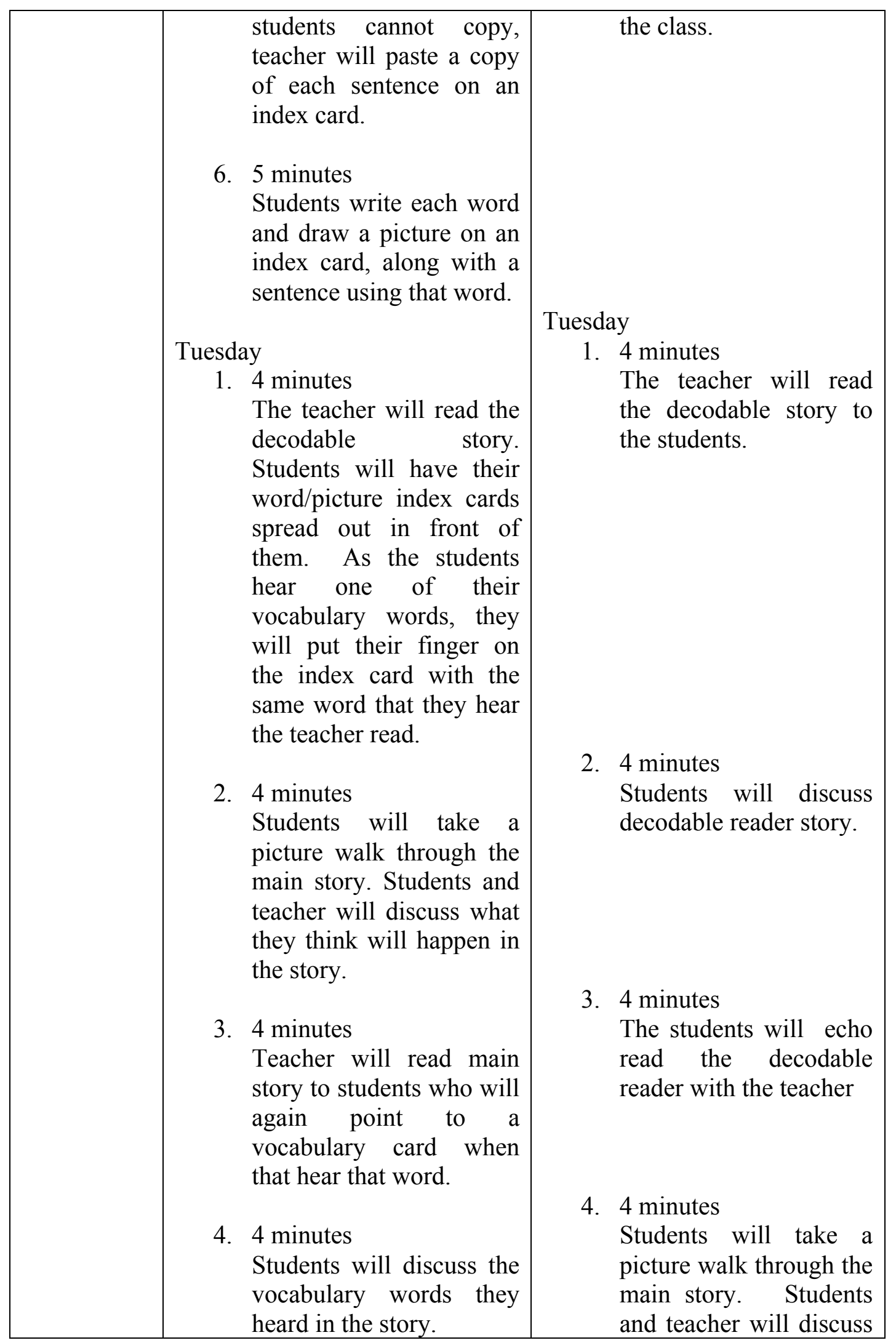




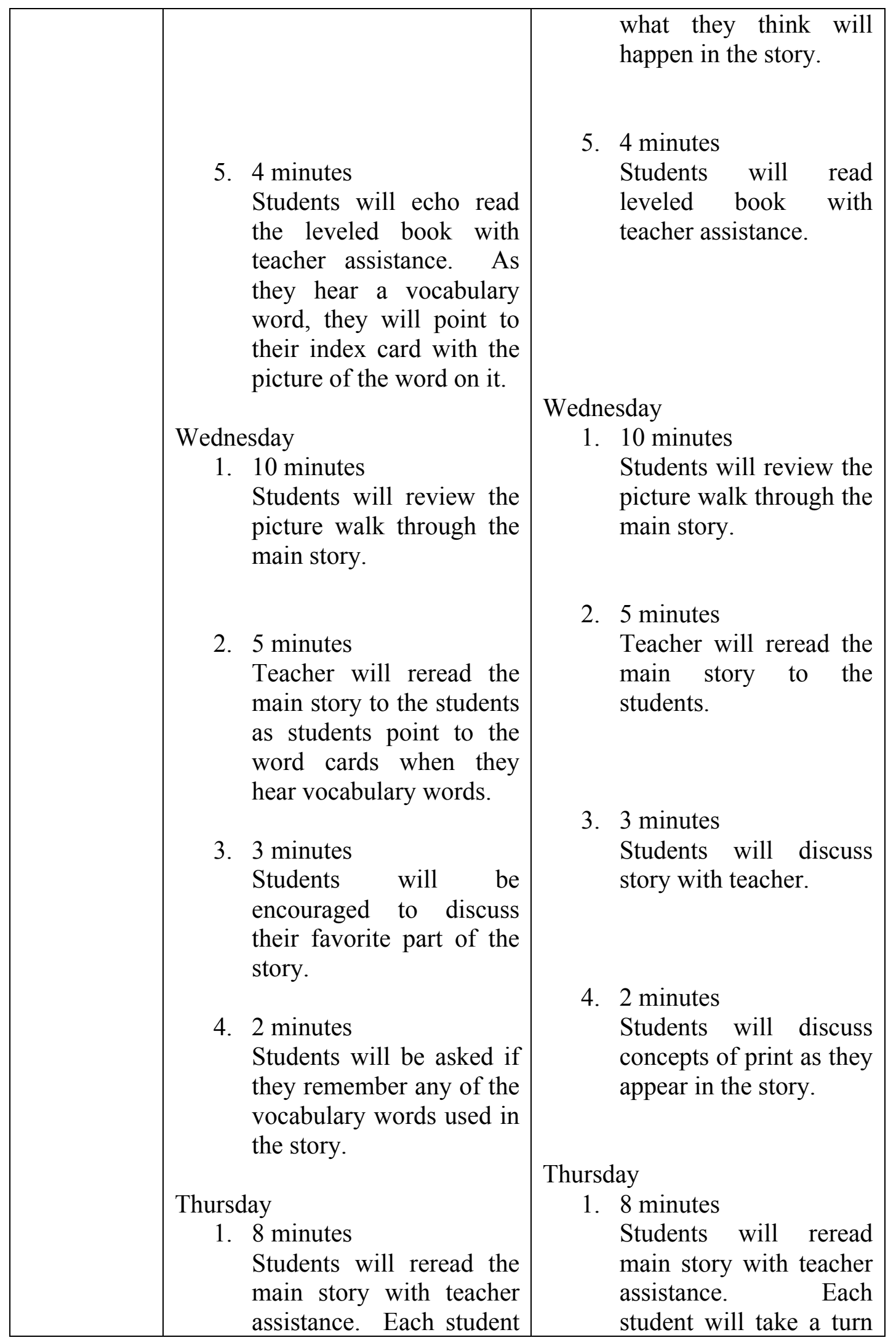




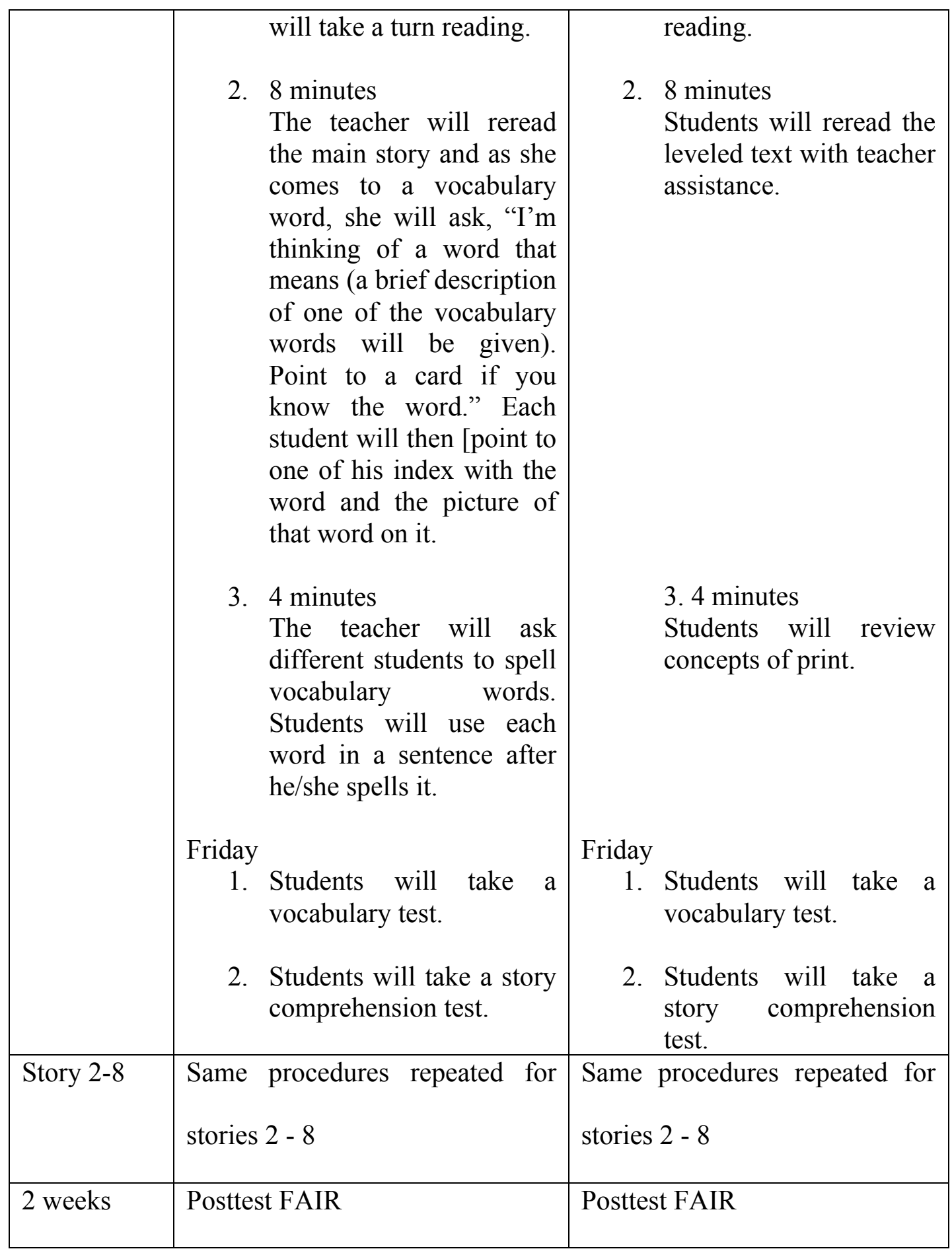




\section{APPENDIX G}

\section{Training Manual}

\section{Comparison Group (Traditional) Daily Procedures}

Monday

Each Monday for the comparison group, students will copy the ten vocabulary words into their school agendas. Read and explain each vocabulary word to the students. Ask students to use a vocabulary word in a sentence to be said aloud to the class.

Tuesday

On Tuesday in small group, the students will read the decodable book aloud with teacher assistance and discuss it. Then have students take a picture walk through the main story. The students then read the leveled book with teacher assistance.

Wednesday

On Wednesday in small group, read the main story with students echo reading (reading with teacher as she reads). Students will then discuss the story with teacher assistance. Students will talk about concepts of print as they appear in the story. Thursday

On Thursday in small group, students reread the main story, along with the teacher, with each student taking a turn reading. Students reread the leveled text and review concepts of print.

Friday

On Friday, all the comparison group students take the same vocabulary and story comprehension tests as the treatment group students. 


\begin{tabular}{|c|c|}
\hline Time & omparison Group \\
\hline 2 Weeks & $\begin{array}{l}\text { Pretest } \\
\text { FAIR Comprehension } \\
\text { FAIR Vocabulary }\end{array}$ \\
\hline & $\begin{array}{l}\text { Monday } \\
\text { 1. ( } 2 \text { min.) Teacher introduces words. There are six onset and onset- } \\
\text { and rime words, two review words from the week before, and two } \\
\text { high frequency words. This study will look only at the six onset, and } \\
\text { onset-and-rime words. } \\
\text { 2. ( } 2 \text { min.) Teacher discusses Words' meanings } \\
\text { 3. ( } 4 \text { min.) Teacher models use of words in sentences. } \\
\text { 4. ( } 8 \text { min.) Teacher has students copy words into their school } \\
\text { agendas. } \\
\text { 5. ( } 4 \text { min.) Teacher asks students to volunteer to use words in } \\
\text { sentences and say their sentences aloud to the class. } \\
\text { Tuesday } \\
\text { 1. (4 min.) The teacher will read the decodable story to the students. } \\
\text { 2. ( } 4 \text { min.) Students will discuss decodable reader story. } \\
\text { 3. ( } 4 \text { min.) The students will echo read the decodable reader with the } \\
\text { teacher } \\
\text { 4. ( } 4 \text { min.) Students will take a picture walk through the main story. } \\
\text { Students and teacher will discuss what they think will happen in the } \\
\text { story. } \\
\text { 5. ( } 4 \text { min.) Students will read leveled book with teacher assistance. } \\
\text { Wednesday } \\
\text { 1. ( } 10 \text { min.) Students will review the picture walk through the main } \\
\text { story. } \\
\text { 2. ( } 5 \text { min.) Teacher will reread the main story to the students. } \\
\text { 3. ( } 3 \text { min.) Students will discuss story with teacher. } \\
\text { 4. ( } 2 \text { min.) Students will discuss concepts of print as they appear in }\end{array}$ \\
\hline
\end{tabular}




\begin{tabular}{|c|c|}
\hline & $\begin{array}{l}\text { the story. } \\
\text { Thursday } \\
\text { 1. ( } 8 \text { min.) Students will reread main story with teacher assistance. } \\
\text { Each student will take a turn reading. } \\
\text { 2. ( } 8 \text { min.) Students will reread the leveled text with teacher } \\
\text { assistance. } \\
\text { 3. (4 min.) Students will review concepts of print. } \\
\text { Friday } \\
\text { 1. Students will take a vocabulary test. } \\
\text { 2. Students will take a story comprehension test. }\end{array}$ \\
\hline $\begin{array}{l}\text { Stories 2- } \\
8\end{array}$ & Same procedures repeated for stories $2-8$ \\
\hline 2 Weeks & Posttest FAIR Comprehension and FAIR Vocabulary \\
\hline
\end{tabular}

Teachers will be monitored by the researcher on a weekly basis to ensure that the study is being carried out to fidelity. The Reading Specialist will also be checking on a weekly basis to help ensure fidelity. Any and all questions should be directed to the researcher. All supplies needed will be furnished by the researcher as needed. 


\section{APPENDIX H}

\section{Training Manual \\ Treatment Group Daily Procedures}

Monday

Each Monday ten words will be written on the board for the week. Only the onset, and onset-and-rime words will be looked at in this study. Define all words were for the students. Either act out the words, or show a picture or an object for each of the six onset-and-rime words. Model the use of the words aloud in sentences. The students will print each of the six words on an $8^{\prime} \times 10^{\prime}$ index card, and draw a picture of that word on the back, along with the word. The cards will be hole-punched and stored on a ring in an index card box. In small reading groups, direct students to think of a sentence for each vocabulary word. Pick one of the sentences for each word and write it on the board and have the students copy it onto the appropriate index card. Each student will have a separate card with a self-drawn picture and a sentence for each of the onset-and-rime words.

Tuesday

On Tuesday during small reading groups, read aloud the story from the decodable book containing the vocabulary words. Have the students spread their vocabulary index cards out in front of them. When they hear a vocabulary word, they should put their finger on it. Then have the students take a picture walk (look at the pictures) through the main story for the week. Have the students discuss what they think will happen in the 
story. Students again have their six cards spread out on their desks. When the students hear one of the vocabulary words, they point to that index card. Discussions will be held about the words when needed.

Wednesday

On Wednesday in small reading groups, have the students listen to the teacher read the leveled book. They should point to their word cards in front of them as they listen to the story. Reread the main story with the students pointing again to their word cards if they hear a vocabulary word in the story. Direct students to discuss their favorite part of the story.

\section{Thursday}

On Thursday, students reread the main story with teacher assistance. Each student takes a turn reading. The teacher will then read the main story again. When the teacher comes to one of the vocabulary words, she will say, "I am thinking of a word that means (teacher gives a brief description of the word). She directs the students to point to one of their cards if they know the word. Each student will be then asked to make a sentence using one of the vocabulary words.

\section{Friday}

On Friday, all students take both a story comprehension and vocabulary test. 


\section{Time Table for Small Group Reading}

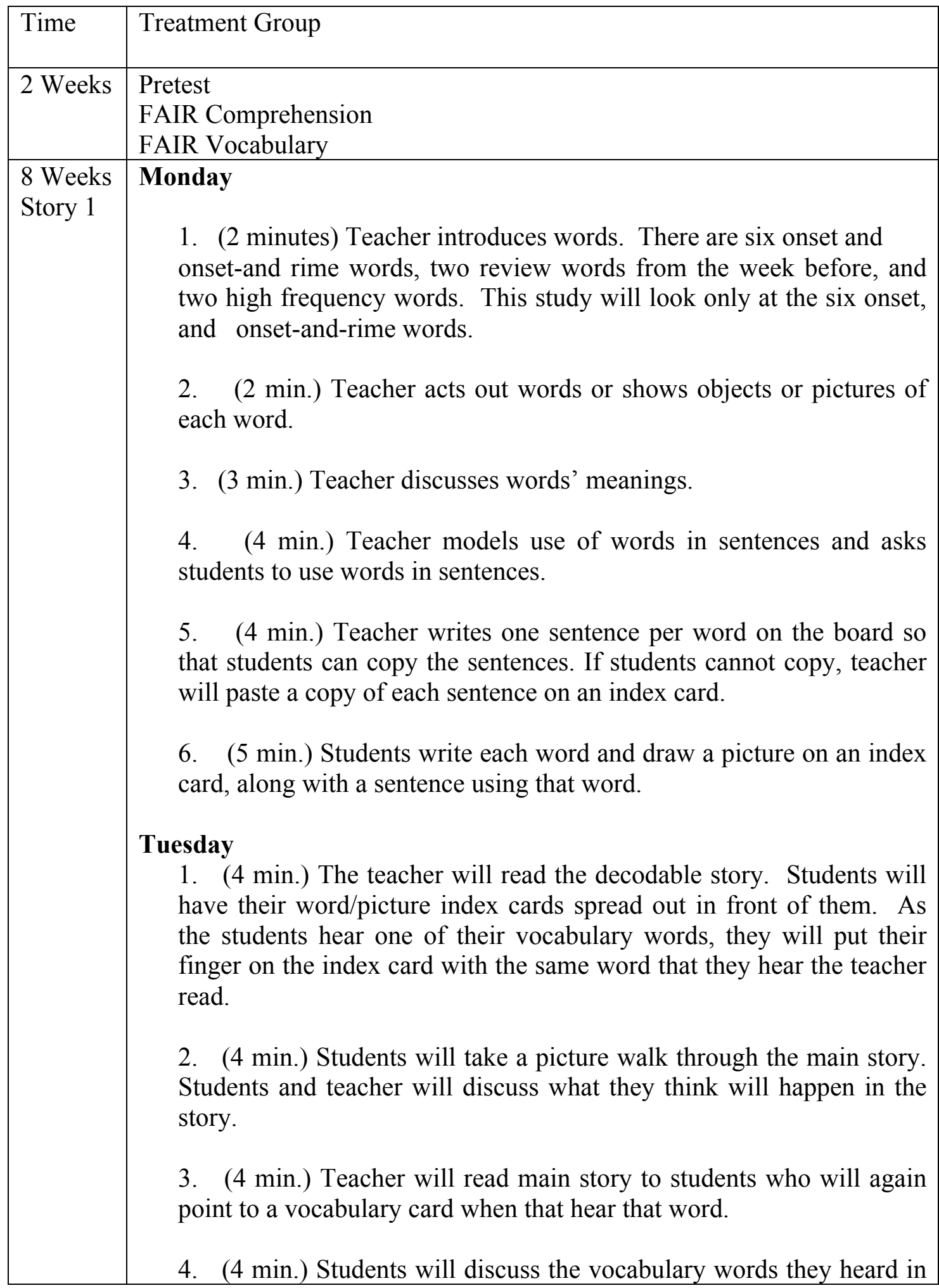




\begin{tabular}{|c|c|}
\hline & $\begin{array}{l}\text { the story. } \\
\text { 5. ( } 4 \text { min.) Students will echo read the leveled book with teacher } \\
\text { assistance. As they hear a vocabulary word, they will point to their } \\
\text { index card with the picture of the word on it. } \\
\text { Wednesday } \\
\text { 1. ( } 10 \text { min.) Students will review the picture walk through the main } \\
\text { story. } \\
\text { 2. ( } 5 \text { min.) Teacher will reread the main story to the students as } \\
\text { students point to the word cards when they hear vocabulary words. } \\
\text { 3. ( } 3 \text { min.) Students will be encouraged to discuss their favorite part } \\
\text { of the story. } \\
\text { 4. ( } 2 \text { min.) Students will be asked if they remember any of the } \\
\text { vocabulary words used in the story. } \\
\text { Thursday } \\
\text { 1. ( } 8 \text { min.) Students will reread the main story with teacher } \\
\text { assistance. Each student will take a turn reading. } \\
\text { 2. ( } 8 \text { min.) The teacher will reread the main story and as she comes } \\
\text { to a vocabulary word, she will ask, "I'm thinking of a word that means } \\
\text { (a brief description of one of the vocabulary words will be given). } \\
\text { Point to a card if you know the word." Each student will then [point to } \\
\text { one of his index with the word and the picture of that word on it. } \\
\text { 3. ( } 4 \text { min.) The teacher will ask different students to spell vocabulary } \\
\text { words. Students will use each word in a sentence after he/she spells it. } \\
\text { Friday } \\
\text { 1. Students will take a vocabulary test. } \\
\text { 2. Students will take a story comprehension test. } \\
\text { Same nrocedures reneated for stories } 2 \text { - } 8\end{array}$ \\
\hline $\begin{array}{l}\text { Stories } \\
2-8\end{array}$ & Same procedures repeated for stories $2-8$ \\
\hline 2 Weeks & Posttest FAIR Comprehension and FAIR Vocabulary \\
\hline
\end{tabular}


Teachers will be monitored by the researcher on a weekly basis to ensure that the study is being carried out to fidelity. The Reading Specialist will also be checking on a weekly basis to help ensure fidelity. Any and all questions should be directed to the researcher. All supplies needed will be furnished by the researcher as needed. 
VITA

VIRGINIA LYNN SHOUP HOLDERNESS

1972

Bachelor of Arts, English Literature

Indiana University, Bloomington, Indiana

1974

Bachelor of Science, Secondary Education

Tri-State University, Angola, Indiana

1974-1976

High School English Teacher

Cocoa Beach High School

Cocoa Beach, Florida

1986

Bachelor of Science, Elementary Education

Nova Southeastern University

Fort Lauderdale, Florida

1986-1999

Director, Southwind Preschool

Plantation, Florida

1999-2013

Teacher

Riverland Elementary School

Fort Lauderdale, Florida

2002

Master's Degree, Reading

Florida International University

Miami, Florida

2011

Specialist Degree, Reading

Florida International University

Miami, Florida

2003-2013

Doctoral Student years

Reading, Curriculum and Instruction

Florida International University

Miami, Florida 